\title{
Visual rehabilitation of patients with oculocutaneous albinism Type I (OCA1): Results in 85 patents
}

\author{
Richard W Hertle ${ }^{1,2,5}$, Dongsheng Yang ${ }^{3}$, Luxin Ma ${ }^{4}$, Jianlu Gao ${ }^{3}$, G Madhavi ${ }^{5}$, Tawna L Roberts ${ }^{1}$ and Sara Otaibi $^{6}$ \\ ${ }^{1}$ Children's Hospital Vision Center, Akron Children's Hospital, Akron, OH, USA \\ ${ }^{2}$ The Northeastern Ohio Medical University, Rootstown, OH, USA \\ ${ }^{3}$ Department of Ophthalmology, Liaocheng People's Hospital, Liaochneg, China \\ ${ }^{4}$ Department of Ophthalmology Shandong Provincial Hospital Jinanm, China \\ ${ }^{5}$ Goutami Eye Institute, RB Nagar, Rajahmundry, India \\ ${ }^{6}$ Children's Hospital of Pittsburgh of UPMC, Pittsburgh PA, USA
}

\begin{abstract}
Purpose: To test the hypothesis that a systematic, combination treatment of patients with oculocutaneous albinism type 1 (OCA 1 ) results in improvement in multiple measures of visual and ocular motor function.

Methods: This is a prospective, interventional case series analysis of clinical and electrophyisological data before and after multimodal visual system therapy in 85 patients with OCA 1 who had no previous treatment. Therapy included a three step approach after adaptation to spectacle correction: 1 ) extraocular muscle surgery, 2) contact lens correction, 3) oral baclofen $\left(\right.$ Lioresal $\left.{ }^{\mathrm{R}}\right)$. Outcome measures included: 1) routine demography and clinical characteristics, 2) binocular best-corrected visual acuity in the null position (BVA), 3) gaze dependent visual acuity (GDVA), 4) primary position strabismic deviation (SD), 5) anomalous head posture (AHP), 6) contrast sensitivity function (CS), and 7) the expanded nystagmus acuity function (eNAFX). All patients were followed at least 12 months. Parametric and nonparametric statistical analysis of outcome measure data above pre- and post-treatment were perfomed using standard software on grouped data using computerized software.

Results: Patient age ranged from 3.6 to 43.1 years (average 16 years). 63\% were male. Follow up ranged from 12-50 mos (ave 15.1 mos). $7 \%$ had an associated systemic diagnosis, 95\% had a significant refractive error, $88 \%$ percent had an AHP, 36\% had a periodic or aperiodic component to their nystagmus. $97 \%$ had strabismus. There were no serious complications from surgery with a reoperation rate of $12 \%$. There were signficant post treatment improvements in mean/median group BVA, GDVA, SD, AHP, CS, and eNAFX.
\end{abstract}

Conclusion: This study supports the hypothesis that using a combination of standard optical, medical and surgical treatments in patients with OCA1 will result in improvements in multiple aspects of ocular motor and visual functions.

Synopsis: This study demonstrates how using a combination of standard medical, optical and surgical therapy results in improvements in ocular motor and visual functions in patients with OCA1.

\section{Introduction}

Oculocutaneous albinism (OCA) is a group of congenital, developmental disorders characterized by a partial or complete loss of melanin in the skin, hair and eyes. Defects in the genes associated with the melanin biosynthetic pathway are responsible, with four major types identified (OCA1A-B, 2, 3, and 4), along with several subtypes depending on the gene mutated [1].The prevalence of OCA1 is estimated between $1 / 17,000$ and $1 / 40,000$ and in the United States but is as high as $1 / 5,000$ in sub-Saharan Africa [1,2]. OCA is caused by mutations at the albino locus in the TYR gene, which codes for tyrosinase, the initial enzyme in the melanin synthesis cascade $[1,2]$. OCA1 is divided into 2 types clinically: OCA $1 \mathrm{~A}$ is characterized by a complete lack of tyrosinase activity and OCA $1 \mathrm{~B}$ is characterized by reduced tyrosinase activity $[1,2]$. In addition to their skin, hair and eye pigmentation deficits, patients with albinism have abnormalities of visual system development including; low visual acuity, severe ametropia, photophobia, light interference, amblyopia, nystagmus, strabismus, poor stereopsis and retinal, optic nerve, chiasmal and postchiasmal maldevelopment [3-5].

In albino animal models, three main visual system cellular disorders have been identified: a reduction in the number of rod photoreceptors, underdevelopment of retinal specialization and a misrouting of temporal retinal ganglion cell axons [5,6]. While the precise role of tyrosinase during each phase of visual system development is incomplete, experiments to determine the point in visual system development at which tyrosinase exerts its effects have been elucidated in animal models [2,6,7]. To ensure that ganglion cells project to the dorsal lateral geniculate body on the appropriate side of the brain, tyrosinase activity may be required during any or all

Correspondence to: Richard W. Hertle, Children's Hospital Vision Center, Akron Children's Hospital, 300 Locust Street Ste 490, Akron, OH 44302-1804, USA, Tel: (330) 535-8000; E-mail: rhertle@chmca.org

Key words: albinism, nystagmus, vision rehabilitation

Received: November 04, 2017; Accepted: November 17, 2017; Published: November 20, 2017 
phases of retinogeniculate pathway development [2,6,7]. Tyrosinase malexpression has also been hypothesized to be causally related to visual system dysfunction by three mechanisms: 1)failure to commit ganglion cells produced from neuroblasts to ipsilateral or contralateral projections, 2) failure to ensure that neuroblasts properly divide and give rise to postmitotic cells, and 3) failure to ensure that cells die or are maintained appropriately during ganglion cell path finding $[2,6,7]$.

Nearly all patients with OCA1 have infantile nystagmus syndrome (INS), an ocular motor disorder of unknown etiology that presents in early infancy. Nystagmus associated with OCA has been classified in many ways, resulting in some confusion and disagreement among clinicians and scientists [8]. The National Eye Institute sponsored workshop, Classification of Eye Movement Abnormalities and Strabismus (CEMAS), has attempted to resolve some of the confusion with a publication that defines the various types of nystagmus associated with OCA [9]. The published definition of INS by the CEMAS working group is used in this study [9]. The major clinical characteristics of INS with variable association include: increased intensity with fixation, decreased intensity with sleep, variable intensity due to eye position in orbit or gaze (eccentric null position), changing direction in different positions of gaze (neutral positions), decreased intensity with convergence (damping), changing direction and/or intensity with monocular occlusion ("latent component"), anomalous head posturing, strabismus and dissociated horizontal and vertical deviations [8-10]. In addition to the above characteristics, up to $33 \%$ of patients with OCA1 and INS will have an inherent, rhythmic, periodic or (a)periodically changing nystagmus intensity and/or direction over time [11-14]. Most clinicians are familiar with this oscillation as acquired periodic alternating nystagmus (PAN). Acquired PAN has a specific pattern identified by the presence of spontaneous nystagmus in the primary position, which beats horizontally in one direction for 1 or 2 minutes, followed by a quiet period, and then reappearance of the nystagmus in the opposite direction for a similar length of time [15]. Acquired PAN is usually seen in association with vestibulo-cerebellar disease and neurodegenerative conditions such as Friedreich's ataxia, or vision loss [15]. Infantile aperiodic alternating nystagmus (IAPAN) has all the characteristics of INS except that the nystagmus direction and/or intensity changes in an irregular pattern over time $[16,17]$. IAPAN also has the clinical characteristics of a dynamic, anomalous head posture and dynamically changing visual functions both over time and as a function of gaze $[16,17]$.

Eye movements oscillations showing increasing velocity slow phases are pathognomonic in INS and will differentiate between acquired PAN and IAPAN. In acquired PAN regular changes in intensity and direction are evident and predominantly jerk fast phases are associated with linear or minimally decreasing velocity slow phases. Eye movement recordings of patients with IAPAN will regularly or irregularly change in direction and/or intensity and beats of nystagmus will display one of several waveforms characteristic of INS along with their increasing velocity slow phases. Although neuroimaging is obtained in all cases of acquired PAN, it is not necessary in patients with IAPAN as there is no known associated central nervous system pathology.

The anatomical and physiological consequences to the visual system include: iris, optic nerve and retinal maldevelopment, ametropia, strabismus, amblyopia, nystagmus, photophobia, light interference, periorbital skin malignancy, anomalous head positioning, decreased central visual acuity, decreased contrast sensitivity, and decreased gaze dependent visual acuity and visual recognition time $[1,2,18,19]$. The visual and facial characteristics have been shown to contribute to more broad psychosocial effects such as decreased eye contact, poor selfesteem and confidence and, in some cultures, a risk of dismemberment or death [20].

Two broad areas of visual system treatment in patients with albinism include treating their ametropia and ocular motor dysfunctions $[21,22]$. Common standard visual system treatment of patients with OCA 1 includes, correction of refractive errors with spectacles, treatment of amblyopia, eye muscle surgery for strabismus, low vision devices, sunglasses and skin protection [21,22]. Although treatment of refractive error is standard of care, the use of devices such as specialized contact lenses is often not included. Likewise, treatment of strabismus and amblyopia is common, but associated treatment of nystagmus and its consequences are rare.

This report details the outcome of a combination 3-step approach to the treatment of patients with OCA 1 after baseline spectacle correction. These steps included eye muscle surgery, peripherally painted contact lenses and oral Baclofen $\left(\right.$ Lioresal $\left.{ }^{\mathrm{R}}\right)$. Each treatment was indicated for a specific set of visual system abnormalities charactersitic of patients with OCA1.

\section{Methods}

All testing, data collection, analysis and reporting were approved by the Institutional Review Board of Akron Children's Hospital, Akron, OH USA and The Children's Hospital of Pittsburgh of UPMC, Pittsburgh, PA USA. All procedures observed the declaration of Helsinki and informed consent/assent was obtained from all patients/ parents. Inclusion criteria for patients with OCA1 included: congenital severe hypopigmentation of hair, skin, nails, choroid and retinal pigment epithelium, iris transillumination, foveal hypoplasia, and INS (diagnosed by eye movement recordings), no prior treatment other than spectacles and not taking any medications known to affect the ocular motor system. Exclusion criteria included those patients with syndromic albinism (except Hermansky-Pudlak Syndrome, mild developmental delay, or associated Septo-Optic Dysplasia). Patients in whom there were incomplete data or follow up less than 12 months were excluded from this report.

\section{Interventions}

$1^{\text {st }}$ Intervention-Spectacle Therapy-Baseline visual function: The first step of intervention was to prescribe spectacle optical correction. Many patients presented either for the first time or for another treatment opinion who were not already in spectacles. The spectacles prescribed fully corrected myopia $>0.75$ diopters, astigmatism $>1.50$ diopters and anisometropia $>1.00$ diopters and either fully corrected or symmetrically under-corrected (by up to $1.50 \mathrm{D}$ ) hyperopia of $>$ +3.50 D (spherical equivalent). Spectacle-corrected distance visual acuity was measured at $3 \mathrm{M}$ in the patients' habitual head position using the amblyopia treatment study (ATS) HOTV protocol for patients < 7 years and the ATS ETDRS protocol for patients $>7$ years of age at least every $4(+1)$ weeks after spectacle wear until acuity remained at within 1 line from the prior visit [23]. The visit at which visual acuity remained stable became the baseline for all further measurements. All subsequent measures of visual acuity described below were obtained using the age-appropriate ATS protocol.

$2^{\text {nd }}$ Intervention - Eye muscle surgery: The goals of eye muscle surgery were to simultaneously treat combinations of the patient's strabismus, anomalous head posture and nystagmus with one 
operation. Standard methods of preoperative evaluation, anesthesia and fornix based eye muscle surgery were employed in the surgical treatment of all patients. The exact surgical procedure for each patient was based on the surgeon's clinical experience and published reports detailing those used in the treatment of strabismus, anomalous head posture, and nystagmus [24]. The surgical procedures are outlined in table 1.

$3^{\text {rd }}$ Intervention - Contact lenses: All patients were fit with daily wear contact lenses. The use of contact lenses in the OCA1 population included the following goals: total refractive error correction, treatment of photophobia (pain from light) and light interference (disturbance in acuity or contrast sensitivity due to light), the allowance of some residual head posture unobstructed by an eyeglass frame or lens aberrations/ prismatic effects and improving their nystagmus characteristics [25]. Contact lens fitting was accomplished by an optometrist familiar with the evaluation and management of contact lenses for routine and special medical use (e.g. tinting and peripherally painting lenses).

$3^{\text {rd }}$ Intervention - Oral Baclofen $\left(\right.$ Lioresal $\left.^{\mathrm{R}}\right)$ : Patients with OCA1 who had IAPAN on eye movement recordings were prescribed Baclofen $\left(\right.$ Lioresal ${ }^{\mathrm{R}}$ ). Baclofen was prescribed orally based on total body mass index as recommended by previous studies, but in general doses of $5 \mathrm{mg}$ TID for patients under 10 years of age, $10 \mathrm{mg}$ TID for patients between 10-15 years of age, and $20 \mathrm{mg}$ TID for those patients over 15 years of age were prescribed.

\section{Outcome variables}

Measures prospectively analyzed for this study included: 1) routine demography and clinical characteristics, 2) binocular best-corrected visual acuity in the null position (BVA), 3) best gaze dependent visual acuity (GDVA), 4) primary position strabismic deviation (SD), 5) anomalous head posture (AHP), 6) contrast sensitivity function (CS), and 7) the expanded nystagmus acuity function (eNAFX). All patients were followed at least 12 months. Standard clinical monitoring of surgical and contact lens complications and side effects of baclofen were performed. While all clinical measures were obtained after each treatment modality, the reported post-treatment measures were obtained 2-6 months after each patient's final treatment.

Table 1. Percentage Of Patients Who Had Each one of Operations 1-9.

\begin{tabular}{|c|c|}
\hline OPERATION TYPE (85 PATIENTS) & \# (\%) \\
\hline $\begin{array}{l}\text { Operation } 1 \text { - Horizontal Head Posture Alone } \\
\text { Horizontal Rectus Recess and Resect or Recess and Tenotomy + Reattach }\end{array}$ & $5(6)$ \\
\hline $\begin{array}{l}\text { Operation } 2 \text { - Chin Down Head Posture (+/- Strabismus) } \\
\text { Superior Rectus Recess } 5.0 \mathrm{~mm}+\text { Inferior Oblique Myectomy }\end{array}$ & $54(64)$ \\
\hline $\begin{array}{l}\text { Operation } 3 \text { - Strabismus Alone } \\
\text { Primary Position Deviation Using at Least Two Recti Each Eye }\end{array}$ & $10(11)$ \\
\hline $\begin{array}{l}\text { Operation 4- Horizontal Head Posture }+ \text { Strabismus } \\
\text { Fixing Eye Straightens Head + Non-fixing Eye Straightens Eyes }\end{array}$ & $10(11)$ \\
\hline $\begin{array}{l}\text { Operation } 5 \text { - Chin Up Head Posture (+/- Strabismus) } \\
\text { Inferior Rectus Recess } 5.0 \mathrm{~mm}+\text { Superior Oblique Tenectomy } 5.0 \mathrm{~mm}\end{array}$ & $5(6)$ \\
\hline $\begin{array}{l}\text { Operation } 6 \text { - No Head Posture, Strabismus or Vergence Damping } \\
\text { Horizontal Rectus Tenotomy + Reattach }\end{array}$ & $\mathbf{0}(\mathbf{0})$ \\
\hline $\begin{array}{l}\text { Operation } 7 \text { - Multiplanar Head Posture (+/- Strabismus) } \\
\text { Transposition of Recti + Combinations of Oblique or Recti Recess }\end{array}$ & $1(2)$ \\
\hline $\begin{array}{l}\text { Operation } 8 \text { - Vergence Damping Alone (Artificial Divergence) } \\
\text { Medical Rectus Recess 3.0 mm + Lateral Rectus Tenotomy + Reattach }\end{array}$ & $\mathbf{0}(\mathbf{0})$ \\
\hline $\begin{array}{l}\text { Operation } 9 \text { - Torsional Head Posture Alone } \\
\text { Horizontal Transposition of Vertical Recti } 1 \text { Tendon Width }\end{array}$ & $\mathbf{0}(\mathbf{0})$ \\
\hline
\end{tabular}

These 9 operations describe a methodological approach to eye muscle surgery on patients with infantile nystagmus syndrome and are based on multiple, previous publications. \# = number of patients, $(\%)=$ percentage of patients, $\mathrm{mm}=$ millimeters, reattch $=$ reattachment of muscle at original insertion with no recession or resection.

\section{Clinical and ocular motor evaluation}

Demographic and clinical data reported in this series includes: age, sex, AHP, ocular alignment, presence of PAN, IAPAN, associated systemic diseases and refractive error. Ocular motor examination included a determination of heterophoria/tropia at distance $(>3 \mathrm{~m})$ and near $(33 \mathrm{~cm})$ in all diagnostic positions of gaze. Cycloplegic refraction, tonometry, and examination of the anterior and posterior segments were performed on all patients. Clinical evaluation of the ocular motor oscillations included changes in the oscillation in primary position, at near, in all nine diagnostic positions of gaze, under monocular and binocular conditions and over time ( $\sim 5$ minutes). As part of our routine evaluation of these patients, fundus photographs and visual evoked potential testing was performed (Table 2 and Figures 1,2).

\section{Visual acuity testing at the null position}

Best visual acuity was measured by a technician trained to perform the ATS visual acuity protocols and they were also masked to treatment status. Visual acuity (VA) testing was performed with the patient's full optical correction in place using the ATS protocol described above [26]. Measurements of best visual acuity (BVA) were obtained both binocularly and monocularly in the patient's habitual head position.

\section{Gaze dependent visual acuity (GDVA) measurements}

Binocular gaze dependent visual acuity (GDVA) was measured at 3 meters across the horizontal visual field from $-20^{\circ}$ (left) to $+20^{\circ}$ (right) in $5^{\circ}$ steps (Figure 3 ) while the patients wore a Cervical Range of Motion device $\left(\mathrm{CROM}^{\mathrm{R}}\right)$ (Figure 4$)$ or a laser assisted 3-Dimensional laser system [27-29]. The $\mathrm{CROM}^{\mathrm{R}}$ device consists of two gravitydependent goniometers and one compass dial on a head-mounted frame allowing measurement of ROM in three planes to ensure that the precision of head position was consistent for GDVA measures at baseline and the post-treatment visit [30]. All visual acuity measures were converted from Snellen equivalent to $\log$ MAR. The change in GDVA was analyzed by performing an area under the curve (AUC) analysis (calculated by integration in Matlab (2014b)) whereby the AUC from each patient represents a spatial area, horizontally between $+/$ - 20 degrees, where their potential best-corrected vision as a function of gaze differs from normal. The AUC represents the patient's potential for improved functional vision space.

\section{Eccentric null zone and abnormal head posture (AHP)}

An additional visual acuity measure was obtained to determine the BVA at the patient's null position in their AHP. The head position required for the patient to obtain their best acuity is recorded from the $\mathrm{CROM}^{\mathrm{R}}$ device.

\section{Eye movement recordings}

All patients had eye movement recordings. The presentation of stimuli, and the acquisition, display and storage of data were controlled by a series of computers using standard Microsoft ${ }^{R}$ and Matlab $^{R}$ software. The horizontal and vertical eye movement recordings were made using the Eyelink ${ }^{\mathrm{R}}$ remote video eye movement system (Eyelink $^{\mathrm{R}}$, SR Research Ltd., Mississauga, Ontario, Canada) with a data sampling rate of 500-1000 Hz. The signals were calibrated (using the end of the fast phase during the nystagmus cycle) at the beginning of the recording session using 3-degree stationary, non accommodative targets presented on a screen at a distance of 1.5 meter from the patient. Calibration was accomplished monocularly, both on line and later by Matlab $^{\mathrm{R}}$ computer program. Fixation was clinically supervised between 
Table 2. Clinical Characteristics Of 85 Patients With OCA1.

\begin{tabular}{|c|c|c|c|c|c|c|}
\hline PT\# & Age & AHP & STRAB & (A)PAN & SX DX & Refractive Error \\
\hline 1 & 43.1 & ALT-DWN & XT-HT & YES & NONE & $(+3.00+2.50 \times 90 \mathrm{OU})$ \\
\hline 2 & 17 & $\mathrm{RF}$ & ET & NO & NONE & $(+4.00+.75 \times 75 \mathrm{OD}, \times 100 \mathrm{OS})$ \\
\hline 3 & 6 & ALT-DWN & ET & YES & DD/GH Def & $(+3.00+4.50 \times 90 \mathrm{OU})$ \\
\hline 4 & 8.1 & DWN & ET & NO & SOD & $(+.50+3.75 \times 90 \mathrm{OU})$ \\
\hline 5 & 6.7 & LF & $\mathrm{XT}$ & NO & NONE & $(+2.00+4.00 \times 120 \mathrm{OD}$ and $\mathrm{X} 60 \mathrm{OS})$ \\
\hline 6 & 8.5 & DWN & ET & NO & DD & $(+2.00 \mathrm{OD},+2.75 \mathrm{OS})$ \\
\hline 7 & 7.5 & DWN & ET & NO & $\mathrm{Sz} \mathrm{D} / \mathrm{O}$ & $(+2.25+2.75 \times 90 \mathrm{OU})$ \\
\hline 8 & 16.6 & DWN & ET & NO & NONE & $(+2.00+2.00 \times 45 \mathrm{OD}, \mathrm{x} 135 \mathrm{OS})$ \\
\hline 9 & 42.3 & DWN & ET & NO & NONE & $(+75+1.75 \times 90 \mathrm{OU})$ \\
\hline 10 & 25.1 & DWN & ET & NO & SOD & $(-3.00+1.50 \times 90 \mathrm{OU})$ \\
\hline 11 & 41.2 & DWN & ET & NO & NONE & $(+3.00+3.50 \times 90 \mathrm{OD},+2.00+2.75 \times 90 \mathrm{OS})$ \\
\hline 12 & 11.2 & DWN & ET & NO & NONE & $(+3.00 \mathrm{OU})$ \\
\hline 13 & 17 & LF & ET & YES & NONE & $(+3.00+4.50 \times 90 \mathrm{OU})$ \\
\hline 14 & 12.1 & DWN & NONE & NO & NONE & $(+1.50+2.50 \times 90 \mathrm{OU})$ \\
\hline 15 & 59.2 & DWN & $\mathrm{XT}$ & NO & DD & $(-4.00+2.50 \times 150 \mathrm{OD},-4.00+1.25 \times 65 \mathrm{OS})$ \\
\hline 16 & 27.4 & DWN & $\mathrm{XT}$ & NO & NONE & $(-5.00+.75 \times 90$ OD) \\
\hline 17 & 34.7 & UP & NONE & NO & NONE & $(-4.00+0.75 \times 180 \mathrm{OD},-4.75+1.00 \times 180 \mathrm{OS})$ \\
\hline 18 & 31.5 & DWN & $\mathrm{XT}$ & YES & NONE & $(\mathrm{PL}+4.50 \times 90 \mathrm{OD}, \mathrm{PL}+5.00 \times 90 \mathrm{OS})$ \\
\hline 19 & 38 & $\mathrm{LF}$ & ET & YES & NONE & $(-1.00+4.50 \times 45,-.75+3.00 \times 135$ OS $)$ \\
\hline 20 & 42.7 & LF & $\mathrm{XT}$ & YES & NONE & $(-1.00+2.00 \times 90 \mathrm{OU})$ \\
\hline 21 & 31 & ALT-DWN & ET & YES & SOD & $(+3.00+6.50 \times 45$ OD, $x 135$ OS $)$ \\
\hline 22 & 6.5 & $\mathrm{RF}$ & ET & YES & NONE & $(\mathrm{PL}+5.50 \times 90 \mathrm{OU})$ \\
\hline 23 & 27.2 & NONE & ET & NO & NONE & $(-5.00+1.00 \times 135 \mathrm{OD}, \mathrm{x} 45 \mathrm{OS})$ \\
\hline 24 & 3.1 & DWN & ET & YES & NONE & $(+2.50+4.50 \times 125 \mathrm{OD}, \mathrm{x} 60 \mathrm{OS})$ \\
\hline 25 & 16.8 & DWN & ET & NO & NONE & $(-7.50+2.25 \times 90 \mathrm{OU})$ \\
\hline 26 & 38.6 & ALT-DWN & ET & YES & HPS & $(+1.00+3.75 \times 60 \mathrm{OD}, \mathrm{x} 120 \mathrm{OS})$ \\
\hline 27 & 7.2 & LF & ET & NO & NONE & $(+4.50+1.25 \times 90 \mathrm{OD}, \mathrm{x} 135 \mathrm{OS})$ \\
\hline 28 & 18 & $\mathrm{RF}$ & ET & NO & NONE & $(+3.00+3.00 \times 90 \mathrm{OD},+3.75+4.00 \times 135 \mathrm{OS})$ \\
\hline 29 & 3.3 & DWN & $\mathrm{XT}$ & NO & NONE & $(-4.75 \mathrm{OU})$ \\
\hline 30 & 10.2 & ALT-DWN & $\mathrm{XT}$ & YES & DD & $(-7.50+1.00 \times 90 \mathrm{OU})$ \\
\hline 31 & 4.1 & DWN & $\mathrm{XT}$ & NO & NONE & $(+5.75 \mathrm{OD},+5.00 \mathrm{OS})$ \\
\hline 32 & 13 & DWN & $\mathrm{XT}$ & NO & NONE & $(-8.50+2.50 \times 90 \mathrm{OU})$ \\
\hline 33 & 3.7 & DWN & $\mathrm{XT}$ & NO & NONE & $(-3.50+4.50 \times 110 \mathrm{OD}, \mathrm{x} 70 \mathrm{OS})$ \\
\hline 34 & 33 & DWN & ET & NO & NONE & $(+1.25+4.25 \times 90 \mathrm{OU})$ \\
\hline 35 & 4.5 & DWN & ET & NO & NONE & $(-2.00+4.00 \times 45$ OD,$-2.25+3.25 \times 110 \mathrm{OS})$ \\
\hline 36 & 13 & UP & ET & NO & NONE & $(+2.25 \mathrm{OU})$ \\
\hline 37 & 15 & DWN & ET & YES & HPS & $(-1.50+4.00 \times 90 \mathrm{OD}, \mathrm{x} 120 \mathrm{OS})$ \\
\hline 38 & 6 & DWN & ET & NO & NONE & $(-5.00+3.50 \times 120 \mathrm{OD},-4.00+4.00 \times 60 \mathrm{OS})$ \\
\hline 39 & 17 & NONE & ET & NO & NONE & $(+2.75 \mathrm{OU})$ \\
\hline 40 & 4 & LF & ET-HT & YES & NONE & $(-.50+1.75 \times 175$ OD, $x 10$ OS $)$ \\
\hline 41 & 5 & DWN & ET & NO & NONE & $(-.75+2.50 \times 140 \mathrm{OD},-1.00+3.00 \times 100 \mathrm{OS})$ \\
\hline 42 & 11 & DWN & ET & YES & NONE & $(+5.50+2.00 \times 90 \mathrm{OD},+5.75+2.00 \times 10 \mathrm{OS})$ \\
\hline 43 & 8.5 & ALT-DWN & ET & YES & NONE & $(+2.00+1.00 \times 90 \mathrm{OU})$ \\
\hline 44 & 15 & DWN & ET & YES & NONE & $(-5.00+4.00 \times 135 \mathrm{OD}, \mathrm{x} 85 \mathrm{OS})$ \\
\hline 45 & 10 & DWN & ET & NO & CEREB & $(-3.00+.75 \times 85$ OD,$-4.50+1.00 \times 100 \mathrm{OS})$ \\
\hline 46 & 6.5 & UP & ET & NO & NONE & $(+2.00+2.50 \times 90 \mathrm{OU})$ \\
\hline PT & Age & AHP & STRAB & (A)PAN & SX DX & Refractive Error \\
\hline 47 & 7 & ALT-DWN & ET & YES & NONE & $(+.75+2.75 \times 90 \mathrm{OU})$ \\
\hline 48 & 9.5 & DWN & ET & YES & NONE & $(+4.00+1.00 \times 90 \mathrm{OD},+3.00+.50 \times 90 \mathrm{OS})$ \\
\hline 49 & 5 & NONE & ET & NO & NONE & $(-4.00+3.00 \times 90 \mathrm{OU})$ \\
\hline 50 & 8.3 & LF & ET & YES & DD & $(-.75+.75 \times 160 \mathrm{OD}, \times 20 \mathrm{OS})$ \\
\hline 51 & 12.5 & NONE & ET & NO & NONE & $(-.50+2.50 \times 90 \mathrm{OU})$ \\
\hline 52 & 8.5 & UP & ET & YES & NONE & $(+6.50 \mathrm{OD},+1.75+1.75 \times 140 \mathrm{OS})$ \\
\hline 53 & 8.5 & $\mathrm{RF}$ & XT-HT & NO & NONE & $(+6.25+1.25 \times 90 \mathrm{OD}, \mathrm{x} 100 \mathrm{OS})$ \\
\hline 54 & 8.5 & NONE & ET & YES & NONE & $(-2.00+4.50 \times 45$ OD, $x 135$ OS $)$ \\
\hline 55 & 3.5 & DWN & ET & YES & NONE & $(-2.50+2.50 \times 90 \mathrm{OD}, \mathrm{PL}+1.00 \times 90 \mathrm{OS})$ \\
\hline 56 & 5.4 & DWN & ET & NO & NONE & $(-1.25+2.75 \times 45 \mathrm{OD},-2.50+1.00 \times 135 \mathrm{OS})$ \\
\hline 57 & 30.4 & UP & ET & NO & NONE & $(+6.00+1.75 \times 105 \mathrm{OD},+5.75+1.75 \times 90 \mathrm{OS})$ \\
\hline 58 & 7 & LF & ET & NO & NONE & $(-5.50+1.7580 \mathrm{OD},-4.75+1.00 \times 180 \mathrm{OS})$ \\
\hline 59 & 4 & ALT-DWN & $\mathrm{XT}$ & YES & SOD & $(-5.00+2.00 \times 90 \mathrm{OU})$ \\
\hline
\end{tabular}




\begin{tabular}{|c|c|c|c|c|c|c|}
\hline 60 & 3.4 & DWN & ET & NO & NONE & $(+2.50+4.50 \times 90 \mathrm{OU})$ \\
\hline 61 & 57 & NONE & ET & NO & NONE & $(+1.00+4.00 \times 45 \mathrm{OD}, \mathrm{x} 135 \mathrm{OS})$ \\
\hline 62 & 4.5 & RF & XT & NO & NONE & $(-5.00+2.00 \times 80$ OD, $-8.00+3.00 \times 75 \mathrm{OS})$ \\
\hline 63 & 47 & ALT-DWN & XT & YES & NONE & $(-4.50+2.75 \times 120 \mathrm{OD}, \quad 525+3.25 \times 60 \mathrm{OD})$ \\
\hline 64 & 35 & DWN & ET & NO & HPS & $(-3.25+2.50 \times 115 \mathrm{OD},-4.50+1.75 \times 110 \mathrm{OS})$ \\
\hline 65 & 16 & DWN & ET & NO & NONE & $(+4.50, \mathrm{OD}+3.25 \mathrm{OS})$ \\
\hline 66 & 8.5 & DWN & ET-HT & NO & NONE & $(-4.00+3.50 \times 80$ OD, $-4.00+4.00 \times 90 \mathrm{OS})$ \\
\hline 67 & 14 & DWN & ET & YES & NONE & $(+6.75+2.25 \times 90 \mathrm{OU})$ \\
\hline 68 & 44 & DWN & ET & NO & SOD & $(-3.00+1.00 \times 185 \mathrm{OD},-3.50+1.50 \times 170 \mathrm{OS})$ \\
\hline 69 & 4 & DWN & ET & NO & NONE & $(-4.25+3.25 \times 60 \mathrm{OD},+2.75+3.50 \times 120 \mathrm{OS})$ \\
\hline 70 & 8 & NONE & XT-HT & NO & NONE & $(-2.50+5.75 \times 15$ OD, $-1.50+6.00 \times 125 \mathrm{OS})$ \\
\hline 71 & 42 & NONE & XT & NO & NONE & $(-3.00+3.25 \times 45 \mathrm{OD},-3.50+2.75135 \mathrm{OS})$ \\
\hline 72 & 6.6 & LF & XT & YES & NONE & $(-1.00+2.25 \times 115 \mathrm{OD},-, 25+4.25 \times 90 \mathrm{OS})$ \\
\hline 73 & 35 & ALT-DWN & ET & YES & NONE & $(-4.00+3.00 \times 120 \mathrm{OD},-2.50+3.25 \times 60 \mathrm{OS})$ \\
\hline 74 & 23 & DWN & ET & NO & NONE & $(-3.75+4.00 \times 90 \mathrm{OD},-3.25+4.00 \times 90 \mathrm{OS})$ \\
\hline 75 & 7.1 & DWN & ET & YES & HPS & $(+3.50+4.75 \times 70 \mathrm{OD},+3.75+5.00 \times 110 \mathrm{OS})$ \\
\hline 76 & 33.5 & DWN & ET-HT & YES & NONE & $(-12.00+3.00 \times 60 \mathrm{OD},-16.00+4.25 \times 120 \mathrm{OS})$ \\
\hline 77 & 11 & RF & ET & YES & NONE & $(+6.50+2.00 \times 90 \mathrm{OD},+5.75+1.75 \times 90 \mathrm{OS})$ \\
\hline 78 & 8 & NONE & ET & NO & NONE & $(-8.50+4.25 \times 115$ OD, $-7.75+3.50 \times 110 \mathrm{OS})$ \\
\hline 79 & 4.5 & NONE & XT & NO & NONE & $(-4.00+0.75 \times 180 \mathrm{OD},-4.75+1.00 \times 180 \mathrm{OS})$ \\
\hline 80 & 3.6 & DWN & XT & NO & DD & $(+3.50+4.75 \times 70 \mathrm{OD},+3.75+5.00 \times 110 \mathrm{OS})$ \\
\hline 81 & 5.8 & DWN & XT & NO & NONE & $(-3.00+2.00 \times 90 \mathrm{OU})$ \\
\hline 82 & 26 & DWN & ET & NO & NONE & $(\mathrm{PL}+3.50 \times 90 \mathrm{OD},+1.75+3.00 \times 90 \mathrm{OS})$ \\
\hline 83 & 13 & UP & ET & NO & NONE & $(+5.25+1.25 \times 90 \mathrm{OU})$ \\
\hline 84 & 11 & DWN & ET-HT & NO & NONE & $(-6.50+1.00 \times 45 \mathrm{OD}, \mathrm{x} 135 \mathrm{OS})$ \\
\hline 85 & 6.3 & DWN & XT-HT & YES & NONE & $(+2.00+4.00 \times 90 \mathrm{OU})$ \\
\hline
\end{tabular}

Clinical characteristics of 85 patients with OCA1. $\mathrm{PT}=$ patient, $\mathrm{Age}=$ in years, $\mathrm{AHP}=$ anomalous head posture, $\mathrm{STRAB}=$ strabismus, $(\mathrm{A}) \mathrm{PAN}=(\mathrm{a})$ periodic alternating infantile nystagmus, SXDX = systemic diagnosis, ALT = changing horizontal head posture associated with $(\mathrm{A}) \mathrm{PAN}, \mathrm{DWN}=$ down, RF $=$ right face, $\mathrm{LF}=$ left face, $\mathrm{XT}=$ exotropia, $\mathrm{ET}=$ esotropia, $\mathrm{HT}=$ hypertropia, DD = developmental delay, GH Def = Growth Hormone Deficiency, SOD = septo-optic-dysplasia, Sz D/O = seizure disorder, HPS = Hermansky-Pudlak Syndrome, CEREB = cerebellar anomaly, $\mathrm{OD}=$ right eye, $\mathrm{OS}=$ left eye, $\mathrm{OU}=$ both eyes.

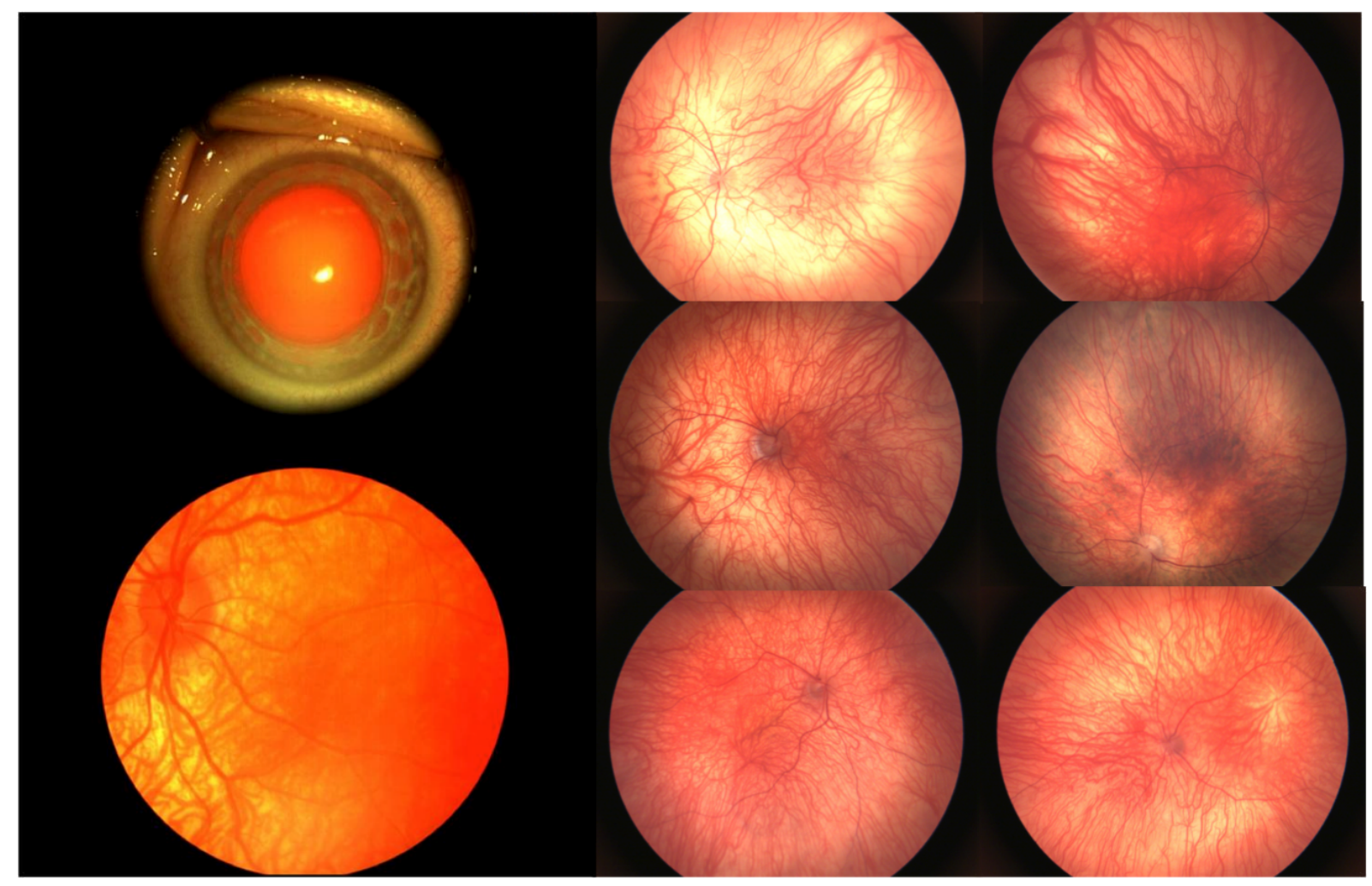

Figure 1. Ocular Findings in Patients with OCA1

Upper left photo shows total iris transillumination using slit lamp retro-illumination. Other photos illustrate typical posterior and mid-peripheral fundus findings in one eye of one patient (lower left) and right and left eyes of 3 patients (upper, middle and lower right photos). These include severe hypopigmentation of the retinal pigment epithelium, and choroid/ choriocapillaris as well as optic nerve and foveal maldevelopment. 


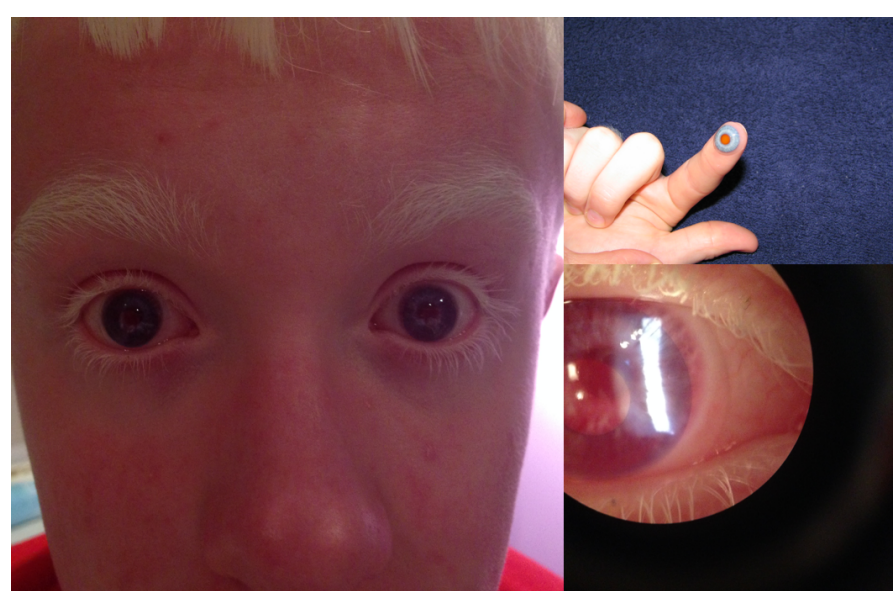

Figure 2. Contact Lens Treatment of OCA1

The photo on the left illustrates the appearance of a peripherally painted contact lenses on both eyes of a patient with OCA1. The photo on the upper right illustrates the appearance of the contact lens on the patient's finger prior to eye instillation. The photo on the lower right is an anterior segment slit lamp photo showing the contact lens in place.

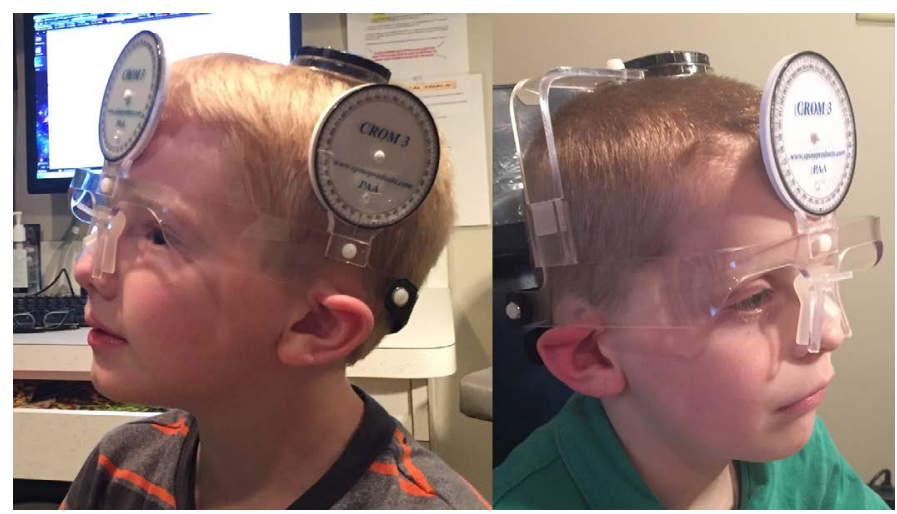

Figure 3. Cervical Range of Motion ${ }^{\mathrm{R}}\left(\mathrm{CROM}^{\mathrm{R}}\right)$ Device For Measurement of Head Position Photo illustrating measurements of head posture used to collect both eccentric null zone position and gaze dependent visual acuity data. A cervical range of motion device $\left(\mathrm{CROM}^{\mathrm{R}}\right)$ is place on the head prior to visual acuity testing. The instrument ensures accurate determination of the head position both during routine binocular best corrected distance acuity testing (eccentric null zone position) and testing acuity as a function of gaze (gaze dependent visual acuity, GDVA).

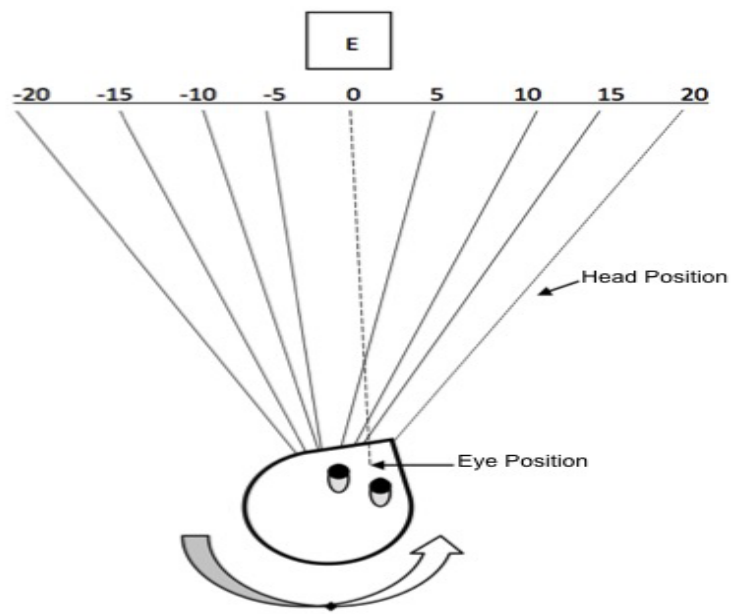

Figure 4. Measurement of Head and Eye Position for Gaze Dependent Visual Acuity (GDVA)

Cartoon showing demonstration of GDVA testing of eyes left 20 degrees by rotating head to the right 20 degrees guided by the $\mathrm{CROM}^{\mathrm{R}}$ mentioned above and in the text.
0 and $30^{\circ}$ horizontally and 0 and $20^{\circ}$ vertically, both in 5 degree steps with both eyes open then fixation at $0^{\circ}$ with both eyes open for 5-10 minutes (to rule out IAPAN. The types of waveforms present were classified according the previously described waveforms associated with INS [31].

\section{The expanded nystagmus acuity function (eNAFX)}

The eNAFX yields, as a number, an indication of the quality of foveation and the potential visual acuity as if no other ocular or central nervous system deficits existed. These effects are restricted to slow eye movements (i.e., saccades are unaffected). Foveation properties, rather than amplitude or frequency, play a key role in determining (potential) visual function in patients with infantile nystagmus syndrome [3133]. The eNAFX predicts the best-corrected visual acuity in subjects with nystagmus, based on objective measurement of their waveform characteristics during fixation of a small non-accommodative target. It combines the foveation time per cycle and the standard deviations of both eye position and velocity during target foveation into a function that is linearly proportional to best-possible visual acuity. Because of idiosyncratic variations in INS waveforms and their foveation periods, satisfaction of both position and velocity criteria are necessary to calculate the eNAFX values that can be reliably compared across subjects. The eNAFX is not dependent on the methodology of data collection (e.g. infrared, video, or magnetic search coil), the type of nystagmus, or their particular nystagmus waveform. To achieve this goal in a user-friendly method, an algorithm that automatically determines the number of foveation periods present in an interval of eye movement data (usually $2-5 \mathrm{~s}$ ) was devised [31]. The interval used to calculate the eNAFX for this study was from the preferred eye, under binocular conditions, during which the patient was constantly fixating the target in their null zone. It cannot contain blinks (or other artifacts) nor periods of inattention. In order to approximate complete cycles, the interval began and ended at or before a foveating saccade. eNAFX and average foveation time were determined using Matlab ${ }^{\mathrm{R}}$. The eNAFX values are between 0 and 1 with a value of $1=20 / 20$ Snellen Acuity and a value of $0=$ No Light Perception.

Fixation intervals under binocular conditions from the patient's preferred eye, in their null zone, from each recording session were averaged and used for data analysis purposes. All eye movement data were analyzed off line (manual selection of fixation periods with computer assisted eNAFX calculation requires about 10-15 minutes per eNAFX number/patient). Mathematical and statistical analysis was done using standard statistical software as part of Excel software program $\left(\right.$ Microsoft $\left.{ }^{\mathrm{R}}\right)$ on a computer spreadsheet.

\section{Contrast sensitivity testing (CS)}

CS was measured using the CSV $-1000 \mathrm{E}^{\mathrm{R}}$ sine wave grating test face $\left(\right.$ Vector Vision ${ }^{\mathrm{R}}$ ) (Figure 5) with the patient seated 2.5 M from the chart. This test provides for four rows of sine wave gratings. At the recommended test distance, these gratings test spatial frequencies of 3, 6, 12 and 18 cycles/degree (cpd). Testing at all spatial frequencies was administered under monocular and binocular conditions after the patient had adapted to room luminance $\left(85.0\right.$ candelas $/$ meter $\left.^{2}\right)$ for 5 minutes. The patient's refractive correction was in place while allowing use of any anomalous head posture necessary to position their gaze in their null zone. CS values were documented in log units (LU). Sensitivity levels at each frequency ranged from 0.70 to $2.08 \mathrm{LU}$ for 3 cpd, 0.91 to $2.29 \mathrm{LU}$ for $6 \mathrm{cpd}, 0.61$ to $1.99 \mathrm{LU}$ for $12 \mathrm{cpd}$ and 0.17 to $1.55 \mathrm{LU}$ for $18 \mathrm{cpd}$. The console of the contrast sensitivity measuring unit provides internal fluorescent luminance calibrated to $85 \mathrm{~cd} / \mathrm{m}^{2}$ 

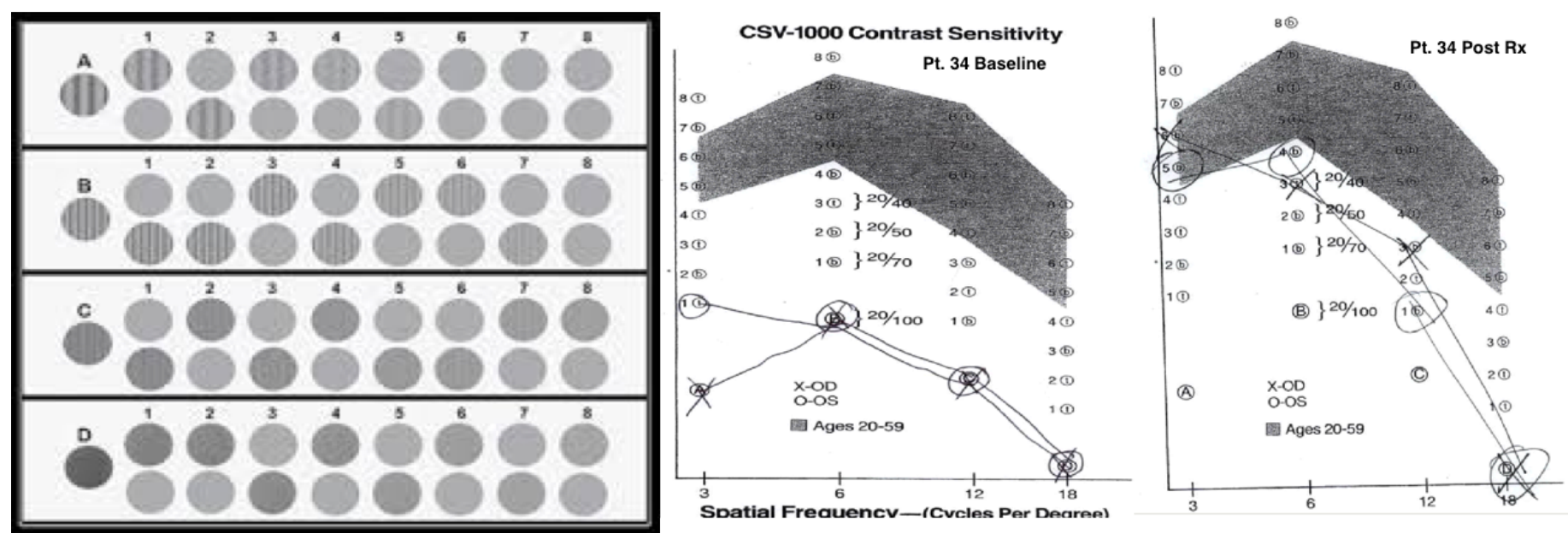

Figure 5. Measurement of Contrast Sensitivity Using the CSV $1000^{\mathrm{R}}$

A photograph of the CSV 1000 light box with stimuli is shown on the left. The patient is asked to identify, for each of the gratings 1-8, the location of the stripes, either; top, bottom or, both gratings are blank. As an example the plot of patient \# 34's contrast sensitivity curve before and after treatment is shown on the right with marks for each stimulus checked and a line connecting the results, creating the contrast sensitivity curve.

for $0.1 \log$ unit instrument light level [34]. The luminance levels were measured with a luminance meter ${ }^{34}$. While reading across the row, the patient was asked to indicate whether the gratings were visible on the top row or the bottom row at each frequency. If the grating was not visible in either patch, the patient's response was recorded as "both blank." The results of the patient's first attempt were considered a trial and the values recorded at the second attempt were used as the CS measurement. The contrast level of the last correct response was taken as the CS threshold.

\section{Statistical analysis}

A paired t-test was used to determine the difference between baseline (after adaptation to spectacles) and post treatment (2-6 months after final treatment) group means for BVA, UAC for GDVA, CS and eNAFX. All reported $p$ values are two-sided using a significance level of $p<0.05$. Group mean analysis of baseline and post treatment AHP was accomplished using a Fisher's exact test. Analyses were conducted using GB-STAT version 10 (Dynamic Microsystems, Inc ${ }^{\mathrm{R}}, 2004$ ). Data analysis for the GDVA data was performed using Stata version 12.1.

\section{Results}

\section{Patient characteristics}

Of 1,923 patients with infantile nystagmus syndrome evaluated between the years $2010-2015,85$ patients with OCA1 are the subjects of this study and ranged in age from 3.6 to 43.1 years (average 16 years). $13 \%$ were under 5 yrs, $42 \%$ under 10 yrs, $62 \%$ under 20 yrs, $79 \%$ under 30 yrs and $21 \%$ over 30 yrs of age. $63 \%$ were male. Follow up after final treatment ranged from $12-50$ mos (ave $15.1 \mathrm{mos}$ ). $7 \%$ of the patients had an associated systemic diagnosis, e.g., Hermansky-Pudlak syndrome, developmental delay, or septo-optic dysplasia. $88 \%$ percent had an AHP. The AHP was predominantly chin down in $63 \%$, however $15 \%$ had a horizontal face turn and $6 \%$ had chin up posture while $64 \%$ had a multiplanar component to their AHP (Figure 6). 36\% of patients had a periodic or aperiodic component to their nystagmus. $97 \%$ of patients had strabismus, $67 \%$ of which had esotropia, $21 \%$ had exotropia, $9 \%$ had a mulitplanar deviation and $3 \%$ had no strabismus. $95 \%$ had a significant refractive error $(>+3.5$ sphere, -1.0 sphere, +1.5 cylinder or 1.5 diopters of anisometropia in any meridian) (Figures 1,2 and Table 2).

\section{Surgery}

The method used to approach surgery on the extraocular muscles of both eyes is represented in Table $1[24,35,36]$. In those who had strabismus surgery, $6 \%$ had operation $1,64 \%$ had operation $2,11 \%$ had operation $3,11 \%$ had operation $4,6 \%$ had operation $5,0 \%$ had operation 6, 2\% had operation 7, $0 \%$ had operation 8 and $0 \%$ had operation 9. The goals of surgery were to treat combinations of the patient's strabismus, anomalous head posture and nystagmus. No patients with fusion prior to surgery lost fusion after surgery. In those patients whose plan included treating an AHP there was a bilateral symmetric minimal limitation of gaze (about 10-15\%) in the opposite direction of the original head posture without an induced vertical, horizontal or torsional gaze incomitance. Ten patients (12\%) had another operation for recurrent strabismus or treatment of a new or recurrent head posture. Of these 10 patients, 8 were re-operated on within the first year and 2 more than one year after the initial procedure. There were no serious surgical complications. All patients had an indication to move (recess, transpose) or remove (resect, tenectomy) the extraocular muscle as part of their procedure, meaning that none were eligible for tenotomy with reattachment alone on the four horizontal recti (operation 6, table 1).

All 85 patients were fitted with contact lenses. Peripherally painted contact lenses (Figure 2) were tried in $59(70 \%)$, tinted soft contact lenses in 17 (20\%) and tinted gas permeable contact lenses in $9(10 \%)$. At the patient's last visit, 70 (82\%) patients were regularly wearing their contact lenses. The remaining 15 patients were not wearing contacts largely due to intolerance or indifference.

Thirty-one (36\%) patients with infantile (A)PAN had treatment with oral Baclofen $\left(\right.$ Lioresal ${ }^{\mathrm{R}}$ ). All patients had improvement in (a) periodicity on eye movement recordings (Figure 7). Twenty-six (84\%) of the 31 patients treated with Baclofen have continued on treatment longterm, in multiple cases for over 5 years. In the other five, treatment was withdrawn due to intolerance of side effects (e.g., somnolence, fatigue, light headedness) in 3 cases, and perceived lack of effect in 2 . The most commonly reported side effect was somnolence, which occurred in most patients initially and disappeared after the first week of therapy. 

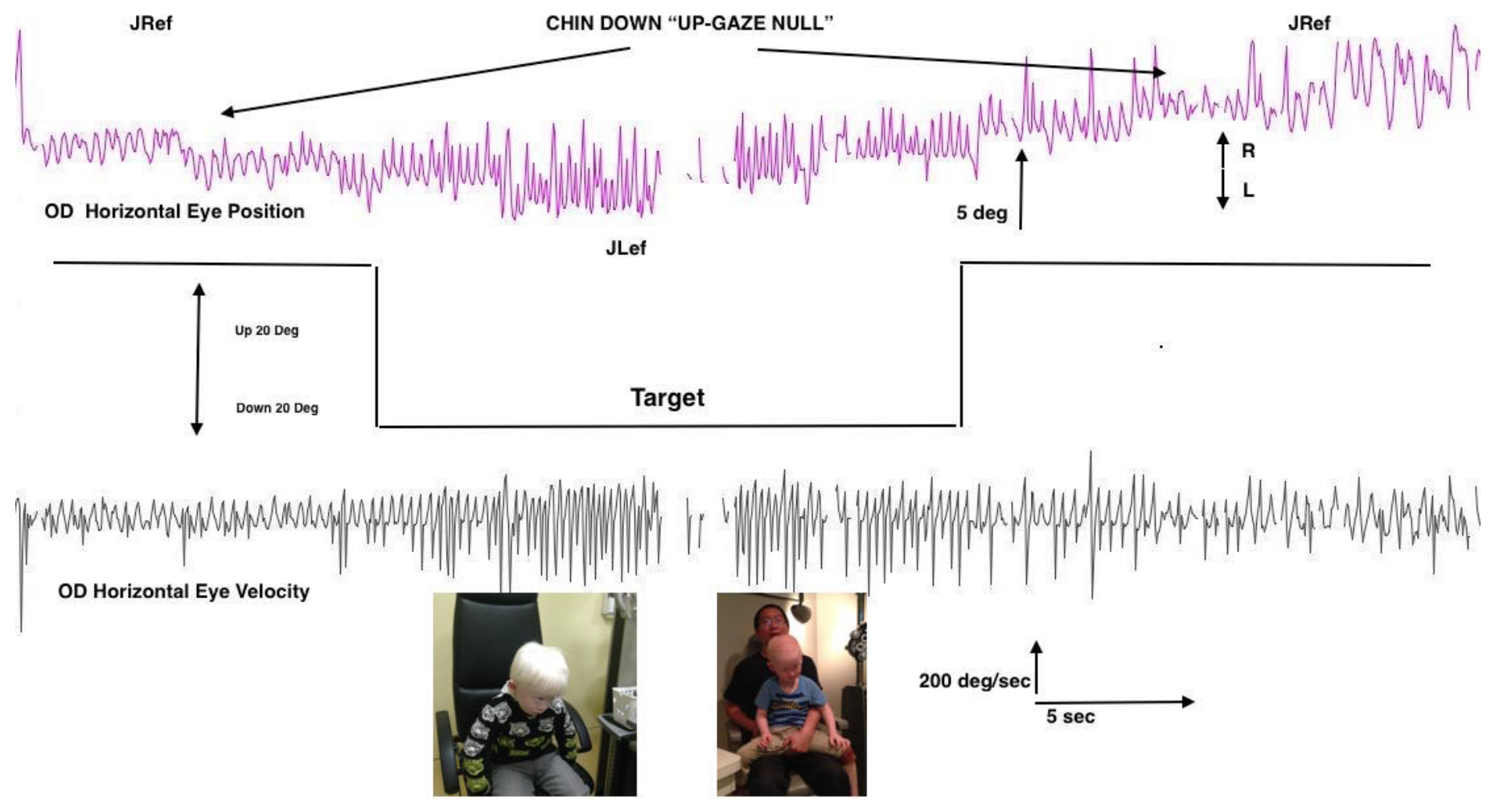

Figure 6. Eye Movement Recordings of "Up-Gaze" Eccentric Null Zone.

This figure shows photos of two OCA1 patients with a common chin-down head position (bottom of figure) resulting from an eccentric null zone in up-gaze. The horizontal eye movement recordings from the right eye of a patient shows what happens to the nystagmus as gaze changes from 20 degrees up (right and left tracings) to 20 degrees down, center tracings. The characteristics of the nystagmus favorably change in up-gaze in both direction and intensity and waveform type. (JRef $=$ jerk right with extended foveation, JLef $=$ jerk left with extended foveation, $\operatorname{deg}=$ degrees, $\mathrm{OD}=$ right eye, $\mathrm{sec}=$ second, $\mathrm{R}=$ rightward eye movement, $\mathrm{L}=$ leftward eye movements).

\section{Visual acuity}

Visual acuity outcome data reported in this study included baseline and at least 2 months and not longer than 6 months after multimodal treatment. We used 2-6 months' post treatment acuity data to allow for complete adaptation to treatments and to avoid natural age-related changes in the younger age group due to visual system maturation. The average group mean BVA improved significantly $(\mathrm{p}<0.05)$ after treatment (baseline BVA $=0.85$, post-treatment BVA logMAR 0.57) (Figure 8 ). Five patients had no change in acuity while $18 \%$, had an increase of $0.1 \log$ MAR, $30 \%$ an increase of $0.2 \operatorname{logMAR}$ and $47 \%$ an increase of $0.3 \log$ MAR. $89 \%$ of patients had a final BVA of better than or equal to $0.70 \log \mathrm{MAR}$, making them eligible for a restricted driver's license in most US States. (Figure 8). Although group means showed improvement in visual acuity, individual patient acuity may have varied +/- $0.1 \log$ MAR based on chance alone. This is inherent in the testing methodology and age of the patients involved in this report and the reason we chose to perform group mean analysis.

\section{Gaze dependent visual acuity (GDVA) outcome}

An example of 4 patient's change in functional vision space between baseline and post-treatment is shown in Figure 9. The group AUC decreased significantly $(\mathrm{p}<0.001)$ between baseline and post-treatment indicating a significant improvement effect of treatment on GDVA and improved functional vision space (Figure 10).

\section{Strabismus deviation (SD)}

There was a significant improvement in the average strabismic deviation in all those intended to correct strabismus. This study was not intended to study the full effect of eye muscle surgery on all the strabismic characteristics, thus full and detailed pre- and post-operative orthoptic data are intentionally excluded except for the single (primary position) outcome measure reported. There was no persistent diplopia after surgery on any patient.

\section{Anomalous head posture (AHP)}

In those patients who had an anomalous head posture at baseline the average change in posture per group improved significantly $(\mathrm{p}<.02)$, were within 8 degrees of straight $(\mathrm{Right} / \mathrm{Left} / \mathrm{Up} / \mathrm{Down})$. It is important to note that in all these patients the predominant direction of their nystagmus oscillation was horizontal, even in those patients with a vertical or multiplanar eccentric gaze null. As is characteristic of INS the intensity of the horizontal oscillation increased away from their gaze null and decreased in their gaze null (horizontally, vertically or torsionally).

\section{Contrast sensitivity (CS)}

Table 3 shows changes in CS at all cycles per degree (cpd) stimuli for baseline and post treatment (final) conditions. CS was statistically significantly better at all cpd stimuli after treatment $(p=0.001)$.

\section{Expanded nystagmus acuity function (eNAFX)}

The group mean change in eNAFX values (0.000 minimum to 1.000 maximum) at baseline was $0.601(+/-0.10)$ which significantly improved to $.426(+/-0.16)$ after treatment (signed rank test, $\mathrm{Z}=3.7$; $p<0.002$ ). (Figures 11, 12) 


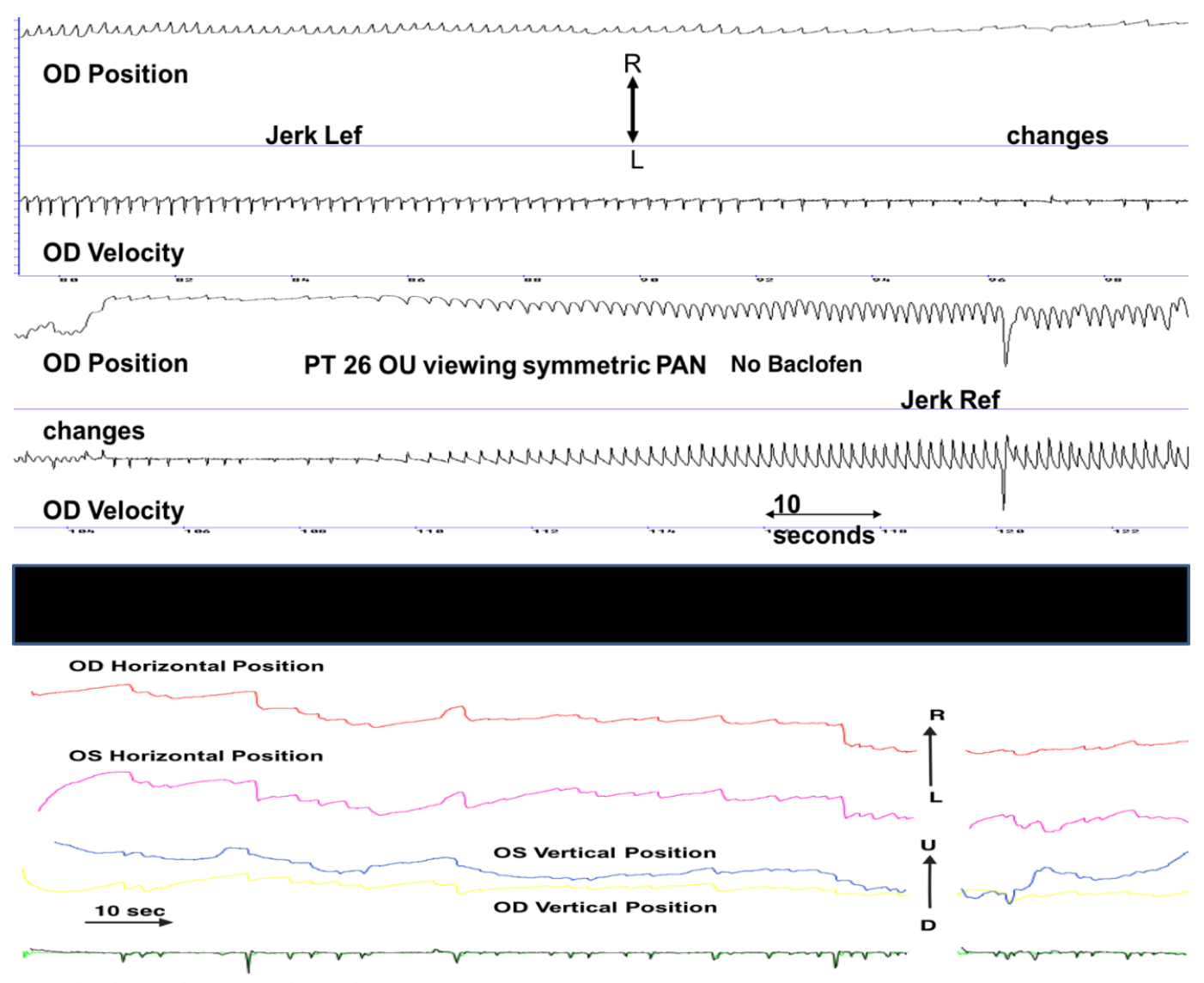

OD (green) and OS (black) Horizontal Velocity

\section{Patient 26 Post Baclofen - PAN}

Figure 7. Eye Movement Recordings After Oral Baclofen

This figure shows eye movement recordings of patient 26 before (top, above black bar) and after (bottom, below black bar) oral baclofen. The top trace displays the patient's right eye position and velocity with a clear, regular pattern of jerk left with extended foveation decreasing in intensity then changing to jerk right with extended foveation over about 3.5 minutes. The bottom trace displays the same patient's right and left eye horizontal and vertical position after oral baclofen. This 1.5 min recording is representative of the patient's continuous state. The periodicity is replaced by less intense, improved jerk with extended foveation waveforms. $(\mathrm{OD}=$ right eye, OS $=$ left eye, $\mathrm{OU}=$ both eyes, Lef $=$ left with extended foveation, Ref $=$ right with extended foveation, $\mathrm{PAN}=$ periodic alternating nystagmus, $\mathrm{R}=$ rightward movements, $\mathrm{L}=$ leftward movements, $\mathrm{U}=$ upward movements, $\mathrm{D}=$ downward movements)

Table 3. Result of Contrast Sensitivity (CS) Testing.

\begin{tabular}{|c|c|c|c|c|}
\hline $\begin{array}{c}\text { Frequency/ } \\
\text { Exam }\end{array}$ & $\begin{array}{c}\text { Mean +/- SD } \\
\text { Log Units }\end{array}$ & $\begin{array}{c}\text { Median } \\
\text { Log Units }\end{array}$ & $\begin{array}{c}\text { Minimum } \\
\text { Log Units }\end{array}$ & $\begin{array}{c}\text { Maximum } \\
\text { Log Units }\end{array}$ \\
\hline 3 cpd $^{*}$ & & & & \\
\hline Baseline & $.70 \pm .33$ & 0.40 & 0.40 & 1.55 \\
\hline Final & $1.53 \pm .38$ & 1.24 & 0.70 & 1.95 \\
\hline 6 cpd & & & & \\
\hline Baseline & $.87 \pm .56$ & 0.68 & 0.68 & 1.77 \\
\hline Final & $1.66 \pm .29$ & 1.44 & 1.01 & 2.11 \\
\hline 12 cpd & & & & \\
\hline Baseline & $.62 \pm .26$ & 0.33 & 0.23 & 1.01 \\
\hline Final & $.96 \pm .24$ & 0.87 & 0.88 & 1.47 \\
\hline 18 cpd & & & & \\
\hline Baseline & $.23 \pm .22$ & 0.11 & 0.11 & 0.91 \\
\hline Final & $.92 \pm .27$ & 0.89 & 0.89 & 1.55 \\
\hline
\end{tabular}

This table summarized the group mean response to CS testing with the CSV $1000^{\mathrm{R}}$ chart at each of the four testing stimuli. There were significant group mean improvements in all four spatial frequency targets after treatment. Frequency $=$ cycles/degree test pattern, Exam $=$ baseline or final, $+/-\mathrm{SD}=$ standard deviation, $\mathrm{cpd}$

*= cycles per degree. Area circumscribed by the rectangle shows significant mean differences at all levels of test pattern performances after treatment.

\section{Discussion}

All types of OCA and ocular albinism have similar ocular findings, including various degrees of early onset nystagmus, hypopigmentation of iris and retinal pigment epithelium, foveal dysplasia, ametropia, strabismus and reduced best-corrected visual acuity (Figure 1) [1,21,22,37]. Photophobia and light interference may be prominent. The abnormal crossing of chiasmatic, post-chiasmatic fibers can be demonstrated by monocular visual evoked potentials [2]. The diagnosis of OCA is usually based on clinical findings of hypopigmentation of the skin and hair, in addition to the characteristic ocular symptoms. However, due to the clinical overlap between the OCA subtypes, other testing such as molecular, electrophysiological or radiological may be necessary. Molecular genetic testing of TYR and OCA2 are available on a clinical basis, while at present, analysis of TYRP1 and MATP is on research basis only.

Visual function in patients with OCA1 is affected by unpredictable combinations of ocular motor (eccentric null zones, damping with convergence, monocularintensity changes, periodicity, strabismus, poor smooth pursuit and OKN and attentional changes) and sensory system defects (ammetropia, amblyopia, photosensitivity, loss of contrast sensitivity, poor motion perception, decreased temporal luminance, impaired contour interaction, light interference and pre-chiasmal, chiasmal, and post-chiasmal, maldevelopment) $[1,2,4,7,11,21,22,38$ - 


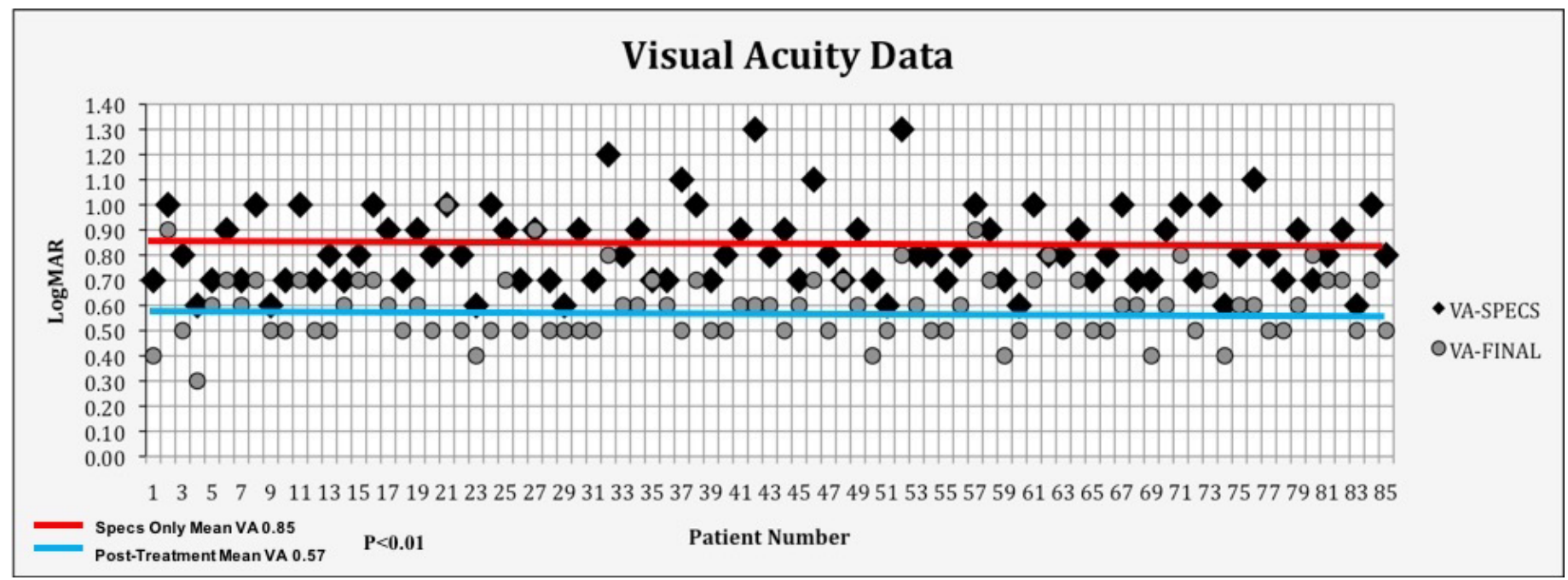

Figure 8. Visual Acuity At Baseline and After Treatment

This figure shows a comparison plot of individual patient and group mean best corrected binocular acuity logMAR acuity at baseline and post-treatment. There was a significant difference for the entire 85 patients ( $<<.01$ group means 0.85 baseline vs. 0.57 post-treatment) (Y axis shows logMAR values from 0 to 1.4 and $\mathrm{X}$ axis shows; patient number, VA= visual acuity, SPECS $=$ spectacles only, FINAL $=$ at least 2 months after treatment $)$.

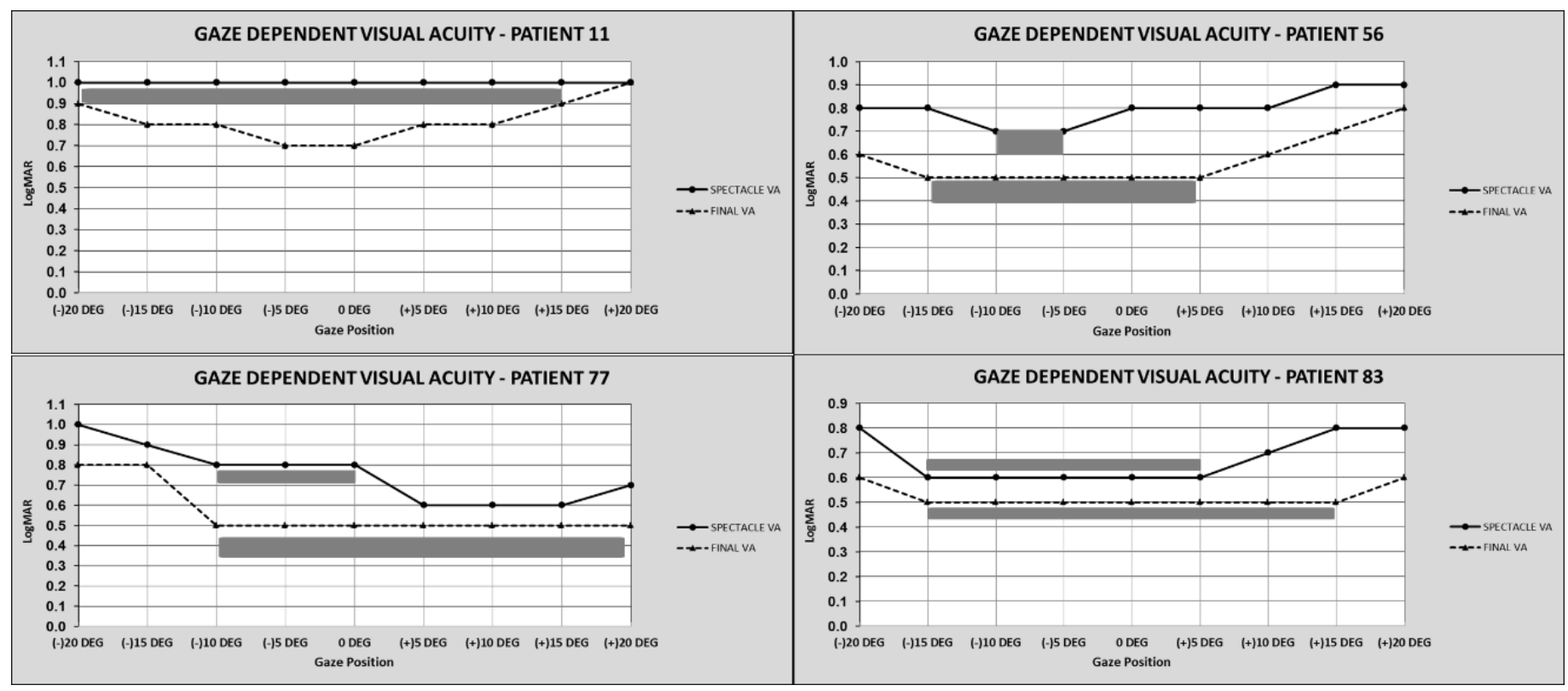

Figure 9. Sample Gaze Dependent Visual Acuity Data (GDVA)

The graphs show GDVA data from four patients (graphs right, left, above and below) at baseline (solid line) and after treatment (dotted line), the shaded grey area shows the change in area of best binocular acuity as a function of gaze after treatment. (logMAR acuity from 0.0 to 1.1 is displayed on the $\mathrm{Y}$ axis, the $\mathrm{X}$ axis shows each position of gaze where visual acuity is tested, $\mathrm{VA}=$ best corrected binocular visual acuity, $\mathrm{DEG}=$ degrees, $(+)$ is gaze to the right, $(-)$ is gaze to the left).

40]. Visual functions directly affected include high spatial acuity vision, contrast sensitivity, motion detection, visual recognition time, gaze and time dependent vision, depth and stereopsis, smooth pursuit, and vestibular and proprioceptive functions $[1,2,4,7,11,21,22,38-40]$. Tests of these visual based functions are usually not part of routine eye evaluations and are more commonly used in research settings but may be important measures of visual function outside the office. It may be that some of all of these visual functions contribute to the subjective improvement in visual "well-being" described by these patients and their families after treatment.

Traditional visual system treatment of patients with OCA1 includes spectacles and routine amblyopia and strabismus management. The use of low vision aids, sunscreens with a sun protection factor of at least 30, avoiding high-risk sun exposure, protective clothing, and eye protection are part of routine suggestions. In the classroom, preferential seating, lighting, computer assisted devices and handouts of board written content are helpful aids.

There is no cure for many of the visual sensory system deficits that are associated with albinism. We hypothesized that a combination of optical, surgical and medical treatments could improve visual function in these patients. This case series supports the hypothesis that optotype visual acuity, contrast sensitivity, gaze dependent vision, vision over time, nystagmus, strabismus and anomalous head posturing can all be improved after a combination optical, surgical and medical treatment. 


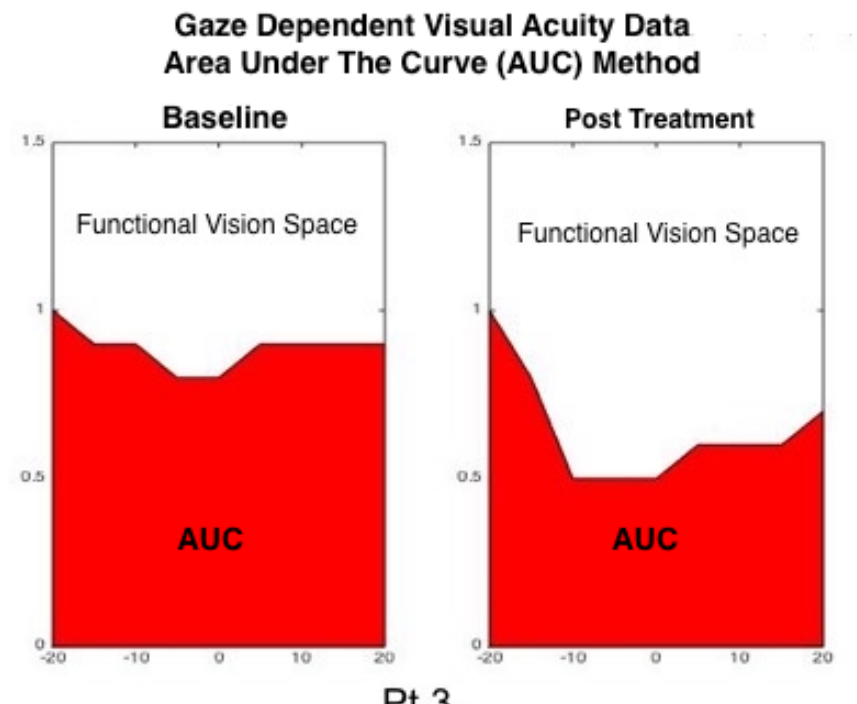

Pt 3

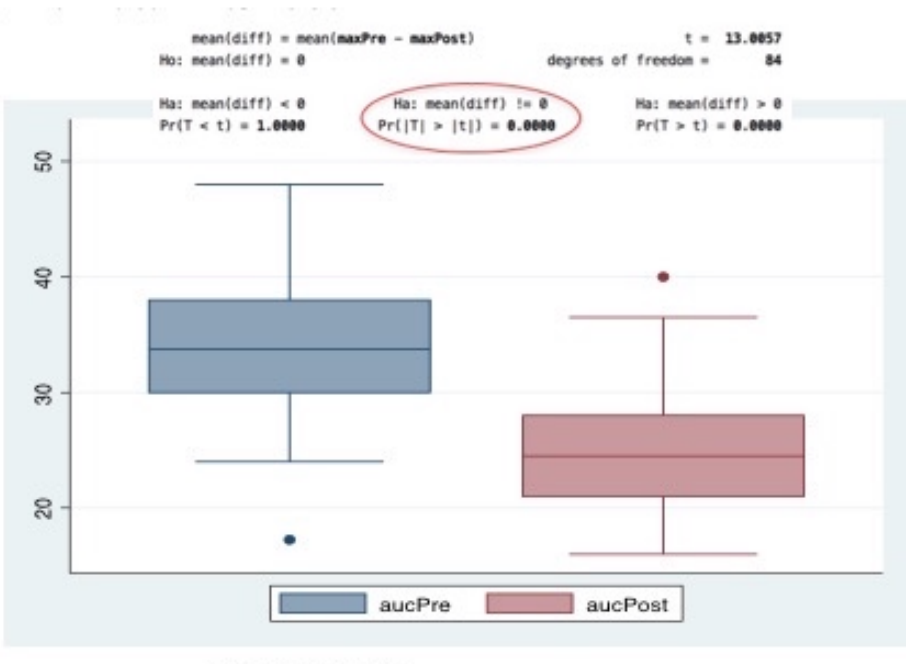

85 Patients

Figure 10. Area Under the Curve (AUC) Data Analysis of Gaze Dependent Visual Acuity (GDVA).

The graphs show AUC data from one patient (figures to the left) at baseline and post treatment, the clear area in the figure represents best-corrected, horizontal, vision space as a function of gaze, while the shaded area under the curve (AUC) represents potential best-corrected vision space. The fight side of the figure shows a box-plot analysis of the entire group GDVA at baseline and post-treatment. The asterisk represents a significant change in GDVA.
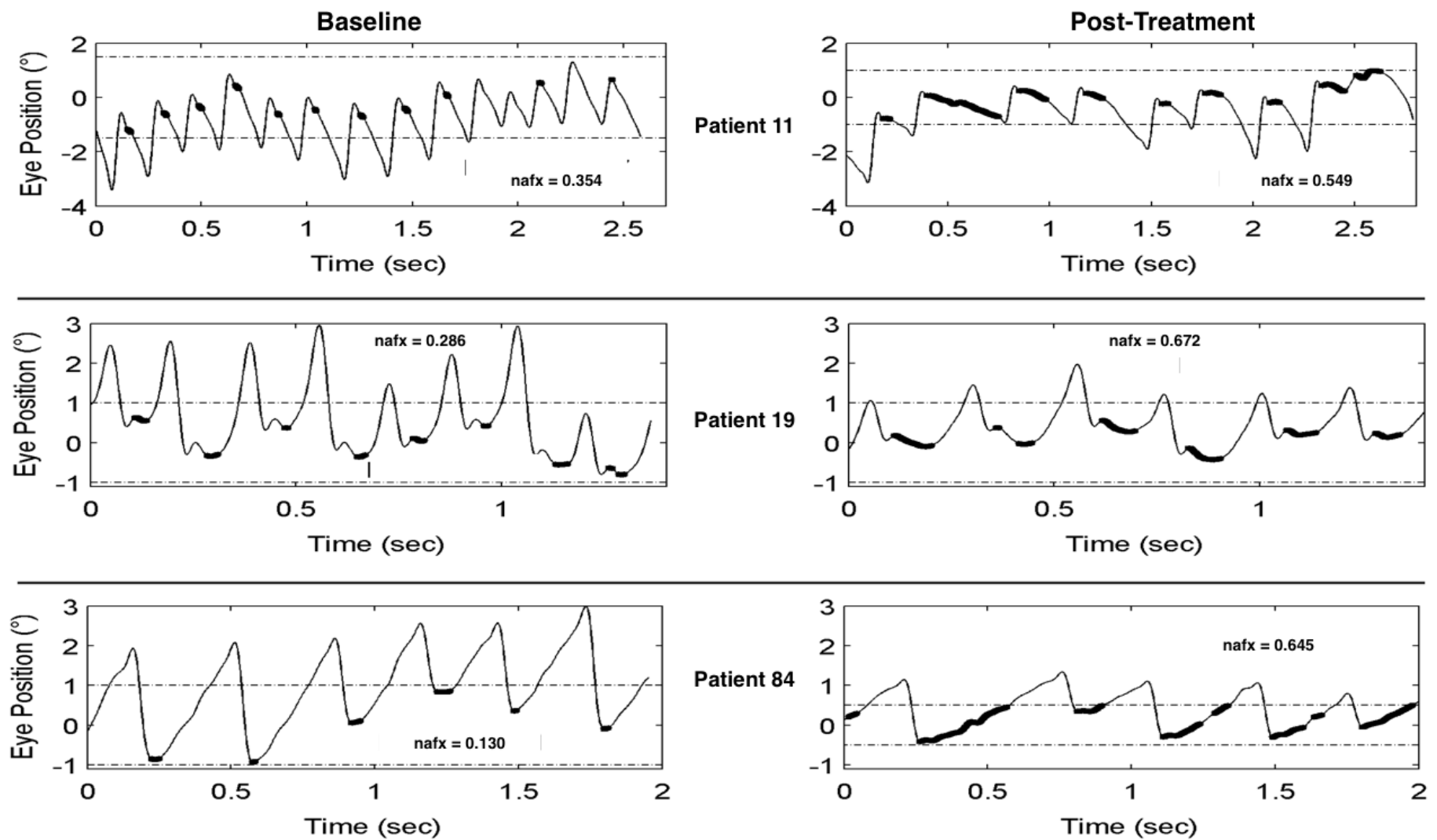

Figure 11. Expanded Nystagmus Acuity Function (eNAFX) Plots

This figure illustrated eye movement data from patients 11, 19 and 84 at baseline and post treatment which is used to calculate the eNAFX. All three patients show jerk with extended foveation waveforms. After treatment waveform amplitude decreased, the number and length of foveation periods (darkened sections of waveform slow phases) increased and the position and velocity variations decreased. The net result was an increased eNAFX. $\sec =\operatorname{seconds},{ }^{\circ}=$ degrees. 


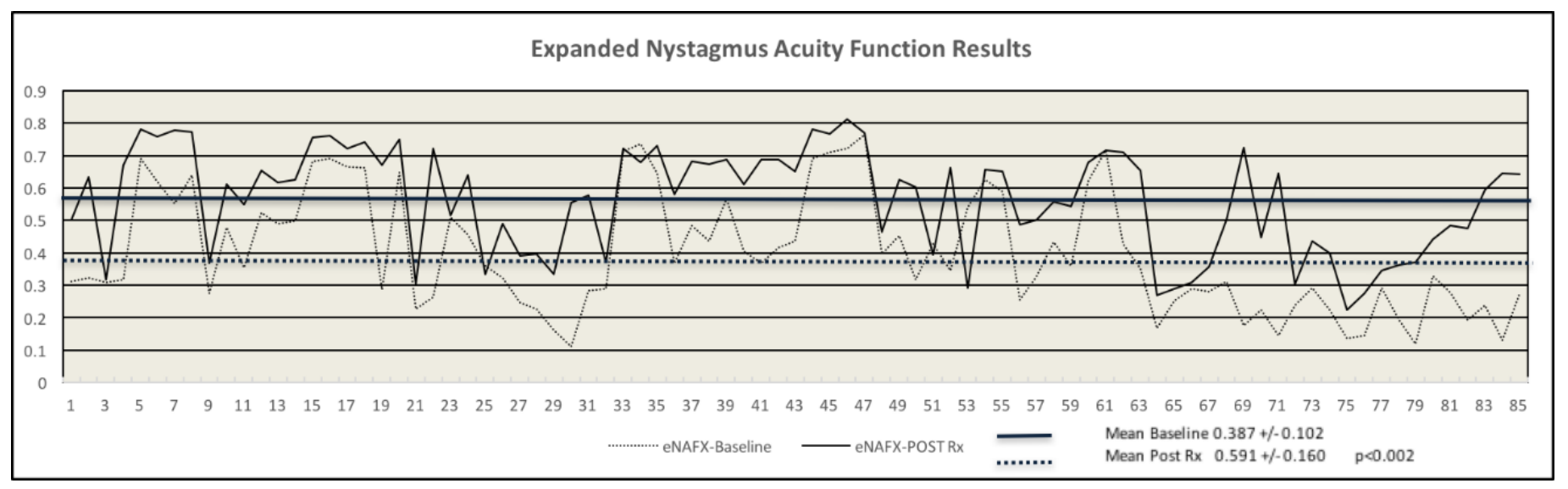

Figure 12. Expanded Nystagmus Acuity Function Results

This figure shows a comparison plot of individual patient and group mean eNAFX results at baseline and post-treatment. There was a significant difference for the entire 85 patients ( $<.002$, group mean $0.387+/-0.102$ baseline vs. $0.591+/-0.160$ post-treatment) ( $\mathrm{Y}$ axis shows eNAFX values from 0 to $1.0, \mathrm{X}$ axis shows patient number, $\mathrm{Rx}=$ treatment)

Treatment directed specifically at the nystagmus would have as its goal to increase the quality and quantity of foveation periods, thereby, increasing the potential for more time and gaze angles during which best visual function could take place. There is a large body of data supporting the hypothesis that foveation periods occurring during each beat of nystagmus can be lengthened or increased by therapeutic interventions (i.e., medicines, surgery, contact lenses, etc.) $[32,35,41-$ 43]. Quantitating these foveation periods is accomplished with accurate, calibrated, eye movement recordings using various foveation programs. We chose the eNAFX as an outcome measure in this report. This study is in agreement with many other reports that show improved foveation (eNAFX values) after treatment. The improvement in INS applies both to patients with and without associated sensory-system defects. Ocular motor and visual system benefits have been shown to be consistently observed in patients who undergo eye muscle surgery for INS, even if the purpose was to decrease torticollis or improve strabismus.

About $9 \%$ to $33 \%$ of patients with INS will have an inherent, rhythmic, periodic or aperiodically changing nystagmus intensity and/or direction over time. Most clinicians are familiar with this oscillation as acquired periodic alternating nystagmus (PAN) [1116,44]. Acquired PAN has a specific pattern identified by the presence of spontaneous nystagmus in the primary position, which beats horizontally in one direction for 1 or 2 minutes, followed by a quiet period, and then reappearance of the nystagmus in the opposite direction for a similar length of time. Acquired PAN can also occur in association with midbrain or cerebellar disease and as an adverse effect of medication such as lithium and anticonvulsants or from loss of vision, e.g., cataracts, vitreous hemorrhage, and optic atrophy [11$16,44]$. Although the mechanism of periodic alternating nystagmus is not clearly understood, lesions of the uvula and nodules as well as structures located in the posterior vermis of the cerebellum, have been shown to be temporally related to its occurrence [45].

Infantile (a)periodic alternating nystagmus (IAPAN) has all the electrophysiological and clinical characteristics of INS except like acquired PAN the null zone shifts position in a regular (periodic) or irregular (aperiodic) pattern [11-16,44]. This results in changes in the intensity and/or direction of the nystagmus and dynamic changes in visual function and anomalous head positioning from seconds to minutes. IAPAN is more common in patients with OCA and, in that clinical setting, is usually not associated with serious central nervous system pathology. Pharmacologically useful agents for patients with nystagmus are primarily GABA agonists or inhibitors of the excitatory neurotransmitter system, including drugs such as gabapentin, memantine and baclofen [46-50]. Over the last 20 years the safe use of oral and intrathecal baclofen has been employed to treat spasticity in patients with cerebral palsy. Several case reports of IAPAN describe a positive effect of baclofen and suggest its effectiveness in patients with IAPAN [46-50]. These reports plus the author's experience with baclofen's use in treating IAPAN was the reason for employing it as part of this treatment protocol.

Several reports suggest it is clinically reasonable to measure CS to assess visual system disability in patients with multisystem vision disease [25,51,52]. Anatomical and electrophysiological anomalies found in human albinos are reflected by reduced contrast sensitivity $[4,53,54]$. Testing of CS in patients with albinism have repeatedly shown it to be abnormal $[4,53,54]$. High astigmatic errors, nystagmus and other retinal/neural anomalies may result in abnormal meridional differences in sensitivity. Previous reports have also shown an increase in peak CS in albino patients while using telescopes and other low vision aids. The data from this report supports deficient CS in OCA1 patients and the potential for subsequent improvement after combined visual system treatment.

A few studies have suggested that the use of contact lenses improves the visual function of patients with INS, although the effects of contact lenses on nystagmus remain debated and only a few clinicians offer this treatment to their patients $[25,41,55-58]$. It is possible that contact lenses may correct a patient's refractive error better than spectacles. The contact lens moves with the eye, therefore the patient looks along the visual axis of the correcting lens for a far greater proportion of the time than with spectacles, especially if an anomalous head posture is used to obtain best visual function. Contact lenses provide more continuous fixation than spectacles, reducing the spherical and chromatic aberration, together with the prismatic effect. In addition, contact lenses generate additional vergence and accommodative effort, both of which decrease INS in some patients. It has also been suggested that contact lens wear may dampen nystagmus by decreasing the nystagmus' amplitude and frequency $[25,41,55-58]$. This phenomenon might be due to sensory feedback from movement of the edge of the lens against the edges and inside of the lids or at the limbus as the eyes oscillate (mediated through trigeminal afferents). Lastly, the contacts can be tinted or peripherally painted reducing glare, photophobia and light interference. 
The prevalence of strabismus averages about $50 \%$ in patients with all types of albinism but varies depending on the phenotype or genetic diagnosis, with a prevalence of almost $100 \%$ in patients OCA1 $[1,2,19,22]$. The most common forms are basic, comitant, esotropia or exotropia, although all motor components of the infantile strabismus syndrome have been reported, i.e., dissociated deviations, apparent over- or under- action of the obliques and alphabet patterns $[1,2,19,22]$. There are also reports of frequent saccadic intrusions in patients with albinism, the sizes of which were correlated with velocities of steady drifts in fixations [59]. This study adds to the evidence of a predominant vertical eccentric gaze null positon with respective anomalous head posture of chin-down or chin-up in patients with albinism $[11,42,60]$. This vertical eccentric gaze null position has been commonly reported with other diseases of the pre-chiasmal visual system, i.e., optic nerve hypoplasia, foveal dysplasia and retinal dystrophy $[11,42,60]$. It may be that clinicians have either not recognized these vertical null positions or there is less experience with its treatment, either way, those patients with a chin-down or chin-up posture are eligible for surgical treatment in the same way, and for the same reason as those with horizontal head postures.

The approach outlined in Table 1 to eye muscle surgery in OCA 1 patients was developed as a result of a need to improve multiple pre-operative ocular motor and/or visual system abnormalities in the patient population with INS. This 9-operation system allows the clinician to maximize surgical intervention by performing one procedure to address all possible indications, e.g., eye position, head/ face position and nystagmus characteristics $[24,35,36]$. This surgical algorithm is based on standard eye muscle surgical techniques and is easily applicable in most clinical situations $[24,35,36]$. The data from this study have shown that OCA1 patient's strabismus and anomalous head posture can be improved after eye muscle surgery in the same way as other populations of patients with strabismus.

The INS population suffers from time (attention, fatigue, illness, medication, IAPAN) and gaze dependent (null zone) changes in their visual function. This results in a peculiar attribute of their vision sense. INS patients have a "dynamic" visual system, whereas the normal sense of vision is "static." If the INS patient's best binocular visual function is dependent on eye position in orbit (gaze) then a restricted 3-dimensional area of vision space exists in breadth, depth and width, which we have labelled "functional vision space." There is no substantial gaze-restricted visual function in the normal visual system, thus normal functional vision space is physiological limits of gaze and distance vision. These factors may reflect real-world visual dysfunction in the INS population. To try and quantitate this anomalous visual physiology we have developed a measure called gaze-dependent visual acuity (GDVA) $[29,33]$. It has been previously reported that measured acuity in INS patients is dependent on gaze angle and visual recognition time $[29,33]$. We have used the GDVA measure in the OCA1 population and demonstrated a significant improvement in functional vision space after treatment.

\section{Study limitations}

There are several limitations of this case series. This is not a randomized clinical trial comparing an isolated intervention to a known treatment or placebo. There are no randomized clinical trials evaluating treatments of albinism thus clear evidenced based guidelines including indications and risks of treating visual system anomalies associated with albinism are based on historical face validity and case/ cohort series such as this one. Although all patients had a "pure" subset of OCA (OCA1), we included patients of all ages, varied baseline visual systems and a few with syndromic albinism. We did not report analysis of each outcome measure after each treatment, but treated the three interventions (optical, medical, surgical) as a single combined therapy, choosing to use baseline and post-treatment measures as our beginning and end points. It may be that one treatment modality, e.g., surgery, may have a more profound effect on one (strabismus) or another (nystagmus) outcome measure. We analyzed and reported combined treatment data because this reflects the standard clinical situation in which, in this patient population, there is an indication for each of the three treatment modalities. We recognize that each treatment (optical, surgical, medical) or possible combinations of treatments, may have had some chance of improving some aspect of visual function due to a unique or overlapping mechanism. Our original and study hypothesis was that the combined treatment effect would improve the selected outcome measures, in a similar manner to combined chemotherapy regimens improving outcomes in cancer treatment.

Although the patients reported here consist one of the largest prospective treatment cohorts of OCA1 patients, this remains level 2-3 evidence at best. The data reported in this study showed significant improvements in BVA, GDVA, CS, AHP, SD, eNAFX from baseline to post treatment, suggesting that these measures of visual function can be improved in patients with albinism after combinations of optical, surgical, or medical treatments. These treatments alone are not novel, nor is treatment of the visual system of patients with albinism. This study has shown that the combined use of standard optical, surgical, and medical treatments of patients with the most severe form of OCA significantly improves their visual function.

\section{References}

1. Grønskov K, Ek J, Brondum-Nielsen K (2007) Oculocutaneous albinism. Orphanet J Rare Dis 2: 43. [Crossref]

2. Lewis RA. Oculocutaneous Albinism Type 1. In: Pagon RA, Adam MP, Ardinger HH et al, eds. GeneReviews(R). Seattle (WA)1993.

3. Marcus RC, Wang LC, Mason CA (1996) Retinal axon divergence in the optic chiasm midline cells are unaffected by the albino mutation. Development 122: 859-868. [Crossref]

4. Pérez-Carpinell J, Capilla P, Illueca C, Morales J (1992) Vision defects in albinism. Optom Vis Sci 69: 623-628. [Crossref]

5. Horsburgh GM, Sefton AJ (1986) The early development of the optic nerve and chiasm in embryonic rat. J Comp Neurol 243: 547-560. [Crossref]

6. Cronin CA, Ryan AB, Talley EM, Scrable H (2003) Tyrosinase expression during neuroblast divisions affects later pathfinding by retinal ganglion cells. J Neurosci 23 : 11692-11697. [Crossref]

7. Ray K, Chaki M, Sengupta M (2007) Tyrosinase and ocular diseases: some novel thoughts on the molecular basis of oculocutaneous albinism type 1. Prog Retin Eye Res 26: 323-358. [Crossref]

8. Abel LA (2006) Infantile nystagmus: current concepts in diagnosis and management Clin Exp Optom 89: 57-65. [Crossref]

9. Hertle RW (2010) Nystagmus in infancy and childhood: characteristics and evidence for treatment. Am Orthopt J 60: 48-58. [Crossref]

10. Thomas MG, Thomas S, Kumar A, Proudlock FA, Gottlob I (1993) FRMD7-Related Infantile Nystagmus. [Crossref]

11. Hertle RW (2013) Albinism: particular attention to the ocular motor system. Middle East Afr J Ophthalmol 20: 248-255. [Crossref]

12. Hertle RW, Reznick L, Yang D (2009) Infantile aperiodic alternating nystagmus. $J$ Pediatr Ophthalmol Strabismus 46: 93-103. [Crossref]

13. Gradstein L, FitzGibbon EJ, Tsilou ET, Rubin BI, Huizing M, et al. (2005) Eye movement abnormalities in hermansky-pudlak syndrome. JAAPOS 9: 369-378. [Crossref]

14. Abadi RV, Bjerre A (2002) Motor and sensory characteristics of infantile nystagmus. $\mathrm{Br}$ J Ophthalmol 86: 1152-1160. [Crossref]

15. Shallo-Hoffmann J, Riordan-Eva P (2001) Recognizing periodic alternating nystagmus Strabismus 9: 203-215. [Crossref] 
16. Gradstein L, Reinecke RD, Wizov SS, Goldstein HP (1997) Congenital periodic alternating nystagmus. Diagnosis and Management. Ophthalmology 104: 918-928. [Crossref]

17. Abadi RV, Pascal E (1994) Periodic alternating nystagmus in humans with albinism. Invest Ophthalmol Vis Sci 35: 4080-4086. [Crossref]

18. Khanal S, Pokharel A, Kandel H (2016) Visual deficits in Nepalese patients with oculocutaneous albinism. J Optom 9: 102-109. [Crossref]

19. Wolf AB, Rubin SE, Kodsi SR (2005) Comparison of clinical findings in pediatric patients with albinism and different amplitudes of nystagmus. J AAPOS 9: 363-368. [Crossref]

20. Cruz-Inigo AE, Ladizinski B, Sethi A (2011) Albinism in Africa: stigma, slaughter and awareness campaigns. Dermatol Clin 29: 79-87. [Crossref]

21. Udeh NN, Eze BI, Onwubiko SN, Arinze OC, Onwasigwe EN, et al. (2014) Oculocutaneous albinism: identifying and overcoming barriers to vision care in a Nigerian population. J Community Health 39: 508-513. [Crossref]

22. Summers CG (2009) Albinism: classification, clinical characteristics, and recent findings. Optom Vis Sci 86: 659-662. [Crossref]

23. Drover JR, Felius J, Cheng CS, Morale SE, Wyatt L, et al. (2008) Normative pediatric visual acuity using single surrounded HOTV optotypes on the Electronic Visual Acuity Tester following the Amblyopia Treatment Study protocol. J AAPOS 12:145-149. [Crossref]

24. Hertle RW, Yang D, Tai Z, Carey K, Mitchell E (2010) A systematic approach to eye muscle surgery for infantile nystagmus syndrome: results in 100 patients. Binocul Vis Strabismus 25: 72-93. [Crossref]

25. Biousse V, Tusa RJ, Russell B, Azran MS, Das V, et al. (2004) The use of contact lenses to treat visually symptomatic congenital nystagmus. J Neurol Neurosurg Psychiatry 75: 314-316. [Crossref]

26. Birch EE, Strauber SF, Beck RW, Holmes JM, Pediatric Eye Disease Investigator G (2009) Comparison of the amblyopia treatment study HOTV and the electronic-early treatment of diabetic retinopathy study visual acuity protocols in amblyopic children aged 5 to 11 years. J AAPOS 13: 75-78. [Crossref]

27. Williams MA, McCarthy CJ, Chorti A, Cooke MW, Gates S (2010) A systematic review of reliability and validity studies of methods for measuring active and passive cervical range of motion. J Manipulative Physiol Ther 33: 138-155. [Crossref]

28. Yang D, Hertle RW, Hill VM, Stevens DJ (2005) Gaze-dependent and time-restricted visual acuity measures in patients with Infantile Nystagmus Syndrome (INS). Am J Ophthalmol 139: 716-718. [Crossref]

29. Hertle RW, Maybodi M, Reed GF, Guerami AH, Yang D, et al. (2002) Latency of dynamic and gaze-dependent optotype recognition in patients with infantile Nystagmus syndrome versus control subjects. Ann N Y Acad Sci 956: 601-613. [Crossref]

30. Burke S, Lynch K, Moghul Z, Young C, Saviola K, et al. (2016) The reliability of the cervical relocation test on people with and without a history of neck pain. J Man Manip Ther 24: 210-214. [Crossref]

31. Dell'Osso LF, Jacobs JB (2002) An expanded nystagmus acuity function: intra- and intersubject prediction of best-corrected visual acuity. Doc Ophthalmol 104: 249-276. [Crossref]

32. Yao JP, Tai Z, Yin ZQ (2014) A new measure of nystagmus acuity. Int J Ophthalmol 7: 95-99. [Crossref]

33. Jacobs JB, Dell'Osso LF, Wang ZI, Acland GM, Bennett J (2009) Using the NAFX to measure the effectiveness over time of gene therapy in canine LCA. Invest Ophthalmol Vis Sci 50: 4685-4692. [Crossref]

34. Kelly SA, Pang Y, Klemencic S (2012) Reliability of the CSV-1000 in adults and children. Optom Vis Sci 89: 1172-1181. [Crossref]

35. Hertle RW, Felius J, Yang D, Kaufman M (2009) Eye muscle surgery for infantile nystagmus syndrome in the first two years of life. Clin Ophthalmol 3: 615-624. [Crossref]

36. Hertle RW, Yang D (2006) Clinical and electrophysiological effects of extraocular muscle surgery on patients with Infantile Nystagmus Syndrome (INS). Semin Ophthalmol 21: 103-110.

37. Brocco G (2016) Albinism, stigma, subjectivity and global-local discourses in Tanzania Anthropol Med 23: 229-243. [Crossref]

38. Schulze Schwering M, Kumar N, Bohrmann D, Msukwa G, Kalua K, et al. (2015) Refractive errors, visual impairment, and the use of low-vision devices in albinism in Malawi. Graefes Arch Clin Exp Ophthalmol 253: 655-661. [Crossref]
39. Kutzbach BR, Merrill KS, Hogue KM, Downes SJ, Holleschau AM, et al. (2009) Evaluation of vision-specific quality-of-life in albinism. J AAPOS 13: 191-195. [Crossref]

40. Holder GE, Gale RP, Acheson JF, Robson AG (2009) Electrodiagnostic assessment in optic nerve disease. Curr Opin Neurol 22: 3-10. [Crossref]

41. Jayaramachandran P, Proudlock FA, Odedra N, Gottlob I, McLean RJ (2014) A randomized controlled trial comparing soft contact lens and rigid gas-permeable lens wearing in infantile nystagmus. Ophthalmology 121: 1827-2836. [Crossref]

42. Hertle RW, Yang D, Adams K, Caterino R (2011) Surgery for the treatment of vertica head posturing associated with infantile nystagmus syndrome: results in 24 patients. Clin Exp Ophthalmol 39: 37-46. [Crossref]

43. Thurtell MJ, Leigh RJ (2010) Therapy for nystagmus. J Neuroophthalmol 30: 361-371. [Crossref]

44. Rust H, Lutz N, Honegger F, Fischer-Barnicol D, Welge-Luessen A, et al. (2016) Periodic alternating nystagmus in a patient on long-term lithium medication. $J$ Neurol Sci 369: 252-253. [Crossref]

45. Oh YM, Choi KD, Oh SY, Kim JS (2006) Periodic alternating nystagmus with circumscribed nodular lesion. Neurology 67: 399. [Crossref]

46. Thurtell MJ, Leigh RJ (2012) Treatment of nystagmus. Curr Treat Options Neurol 14 60-72. [Crossref]

47. McLean RJ, Gottlob I (2009) The pharmacological treatment of nystagmus: a review. Expert Opin Pharmacother 10: 1805-1816. [Crossref]

48. Kumar A, Thomas S, McLean R, Proudlock FA, Roberts E, et al. (2009) Treatmen of acquired periodic alternating nystagmus with memantine: a case report. Clin Neuropharmacol 32: 109-110. [Crossref]

49. Comer RM, Dawson EL, Lee JP (2006) Baclofen for patients with congenital periodic alternating nystagmus. Strabismus 14: 205-209. [Crossref]

50. Uemura T, Inoue H, Hirano T (1988) The effects of baclofen on periodic alternating nystagmus and experimentally induced nystagmus. Adv Otorhinolaryngol 42: 254-259. [Crossref]

51. Singh A, Ashar J, Sharma P, Saxena R, Menon V (2016) A prospective evaluation of retroequatorial recession of horizontal rectus muscles and Hertle-Dell'Osso tenotomy procedure in patients with infantile nystagmus with no definite null position. $J$ AAPOS 20: 96-99. [Crossref]

52. Hertle RW, Reese M (2007) Clinical contrast sensitivity testing in patients with infantile nystagmus syndrome compared with age-matched controls. Am J Ophthalmol 143:1063-1065. [Crossref]

53. Wilson HR, Mets MB, Nagy SE, Kressel AB (1988) Albino spatial vision as an instance of arrested visual development. Vision Res 28: 979-990. [Crossref]

54. Loshin DS, Browning RA (1983) Contrast sensitivity in albinotic patients. Am J Optom Physiol Opt 60: 158-166. [Crossref]

55. Schornack MM, Brown WL, Siemsen DW (2007) The use of tinted contact lenses in the management of achromatopsia. Optometry 78: 17-22. [Crossref]

56. Stahl JS, Plant GT, Leigh RJ (2002) Medical treatment of nystagmus and its visual consequences. JR Soc Med 95: 235-237. [Crossref]

57. Astin CL (1998) The use of occluding tinted contact lenses. CLAO J 24: 125-127. [Crossref]

58. Jurkus JM (1996) Contact lenses for children. Optom Clin 5: 91-104. [Crossref]

59. St John R, Fisk JD, Timney B, Goodale MA (1984) Eye movements of human albinos. Am J Optom Physiol Opt 61: 377-385. [Crossref]

60. Collewijn H, Apkarian P, Spekreijse H (1985) The oculomotor behaviour of human albinos. Brain 108: 1-28. [Crossref]

Copyright: (C2017 Hertle RW. This is an open-access article distributed under the terms of the Creative Commons Attribution License, which permits unrestricted use, distribution, and reproduction in any medium, provided the original author and source are credited. 